Article

\title{
Sunlight Intensity, Photosynthetically Active Radiation Modelling and Its Application in Algae-Based Wastewater Treatment and Its Cost Estimation
}

\author{
Saumya Verma ${ }^{1}$, Raja Chowdhury ${ }^{1, *(\mathbb{D} \text {, Sarat K. Das }}{ }^{2}$, Matthew J. Franchetti ${ }^{3}$ and Gang Liu ${ }^{4}$ \\ 1 Department of Civil Engineering, Indian Institute of Technology, Roorkee 247667, India; \\ saumyaverma459@gmail.com \\ 2 Department of Civil Engineering, IIT_ISM Dhanbad, Dhanbad 826004, India; saratdas@iitism.ac.in \\ 3 Department of Mechanical Industrial and Manufacturing Engineering, University of Toledo, \\ Toledo, OH 43606, USA; Matthew.Franchetti@utoledo.edu \\ 4 Department of Green Technology, University of Southern Denmark, DK-5230 Odense, Denmark; \\ gli@igt.sdu.dk \\ * Correspondence: rajachowdhury1@gmail.com
}

check for updates

Citation: Verma, S.; Chowdhury, R.; Das, S.K.; Franchetti, M.J.; Liu, G. Sunlight Intensity, Photosynthetically Active Radiation Modelling and Its Application in Algae-Based Wastewater Treatment and Its Cost Estimation. Sustainability 2021, 13, 11937. https://doi.org/10.3390/ su132111937

Academic Editor: Alessio Siciliano

Received: 17 August 2021

Accepted: 18 October 2021

Published: 28 October 2021

Publisher's Note: MDPI stays neutral with regard to jurisdictional claims in published maps and institutional affiliations.

Copyright: (c) 2021 by the authors. Licensee MDPI, Basel, Switzerland. This article is an open access article distributed under the terms and conditions of the Creative Commons Attribution (CC BY) license (https:/ / creativecommons.org/licenses/by/ $4.0 /)$.

\begin{abstract}
In algal pond used for treating wastewater, a part of the solar radiation (PAR) is used by algae for photosynthesis, and rest of the solar energy is wasted. To date, no studies have been conducted that optimize these aspects (wasted solar radiation for heat production) from an operational cost perspective. Therefore, a model is developed for the estimation of photosynthetically active radiation (PAR) from solar radiation. Subsequently, derived PAR was utilized in the optimization algorithm. Experimental data on PAR and solar radiation were used to obtain empirical parameters of the developed model. Using empirical parameters, diurnal PAR was estimated for other locations for which the diurnal variation of solar radiation was not available. Afterwards, the estimated solar radiation was used to obtain the cost of algal biomass production using wastewater. For this purpose, a cost function was minimized. The cost function contains various cost components of algae-based wastewater treatment. The major costs of the treatment were incurred by the sunlight harvesting, and distribution equipment, whereas the major income was registered through the conversion of sunlight to heat and biomass production. The yearly cost of treating $1 \mathrm{~m}^{3}$ wastewater in the proposed wastewater treatment plant could be varied from 186 to -44 (Rs, INR). The capital cost of constructing a proposed treatment plant having a capacity of $1000 \mathrm{~m}^{3} /$ day varied from $11-45$ crores INR.
\end{abstract}

Keywords: algal culture; clearness index; modelling of PAR; optimization; wastewater

\section{Introduction}

Dedicated energy crops in the form of various types of grasses indicated a reduction in greenhouse gas (GHG) emission and the cost of biofuels [1,2]. To reduce the GHG emissions and the cost of biofuel further, the uses of waste biomass are found to have several advantages. In this regard, algal biomass provided added advantage of very low land requirement as compared to other biomass feedstocks [3,4]. Incorporating waste nutrients in the form of wastewater reduces GHG emission further [5]. However, producing considerable amounts of algal biomass in wastewater and the treatment of wastewater using algae have several bottlenecks. They are enumerated below: (i) most of these algal strains showed low productivity in wastewater, (ii) diurnal variation of solar radiation may also affect the biomass productivity and wastewater treatment efficiency, (iii) in business as usual cases for algae-based wastewater treatment, one needs to have sufficient sunlight, and thus most of the time it is difficult to increase the depth of the algal ponds beyond $40 \mathrm{~cm} \mathrm{[6].} \mathrm{Hence,} \mathrm{a} \mathrm{strategy} \mathrm{needs} \mathrm{to} \mathrm{be} \mathrm{developed} \mathrm{to} \mathrm{integrate} \mathrm{optimum} \mathrm{solar}$ radiation with algae-based wastewater treatment. For this purpose, solar light harvesting and transport of sunlight can be integrated with algae-based wastewater treatment. Some 
of the studies also used optical fiber-based solar light transport equipment to grow algae in various synthetic mediums $[7,8]$. These studies used optical fibers to provide a fluctuating light source for better algae growth.

Similarly, photoluminescent materials could also be used for harvesting solar light and converting the same to a particular wavelength (red light), which can be optimally used during photosynthesis [9]. The depth limitation increases the land requirement, and at the same time, excessive sunlight during daytime can affect the algal growth by damaging the photosynthetic apparatus of the algal cell. For increasing the depth of the algal ponds and for the optimum distribution of sunlight, providing sunlight harvesting and distribution devices will improve the efficiency of the treatment and may reduce the cost of the treatment. However, the integration of solar light harvesting and its uses for algae-based wastewater treatment and heat production have not been studied for their suitability in biomass production and cost reduction. Solar light harvesting using various types of solar concentrators has been implemented for various beneficial purposes e.g., thermal drying of sludge, hydrothermal liquefaction of biomass for fuels, and daylighting for homes [10-12].

For properly designing solar light harvesting and distribution devices, one needs to have a diurnal variation of solar radiation and photosynthetically active radiation (PAR). PAR is the spectral portion of solar radiation ranging from $400 \mathrm{~nm}$ to $700 \mathrm{~nm}$ used by the plant for photosynthesis [13]. PAR can be measured directly using pertinent instruments or estimated from solar radiation (SR) [14]. However, in most places, the diurnal variations of SR and PAR are not available. Hence, there is a need to develop models for simulating the diurnal variation of PAR and SR.

PAR changes seasonally and varies during the day, and depends on the latitude. Factors affecting the intensity of PAR are sunlight intensity, cloud cover, shading by trees, and buildings. PAR changes from one particular geographical location to another. PAR is a function of the local sky clearness index that depends on the cloud cover, solar declination angle, water vapor concentration, time of the day, and latitude of the location [15].

Studies exist to model solar radiation using either a physics-based model or using soft computing techniques. For example, Hocaoglu and his team [16,17] used Hidden Markov Chain Models to estimate the global solar radiation in various places in Turkey. Bhardwaj et al. [18] used a combination of fuzzy-based and Hidden Markov Chain model for the estimation of solar radiation. Vindel and Polo [19] used the Markov model combined with the Zipf law to develop a solar light intensity estimation model for Spain. Some studies also attempted to estimate or model PAR from solar radiation [20,21]. Some of the models used artificial neural network (ANN), principal component analysis coupled with regression, or artificial neural network to predict solar radiation for a particular area [22,23]. Shams et al. [24] used a time series model to simulate the diurnal variation of solar radiation in Bahrain. Similarly, Sun et al. [21], and Ajayi et al. [25] developed a physics-based model to estimate solar radiation.

Hence, in this study, modelling the photosynthetically active radiation (PAR) from the solar irradiation and vice versa were evaluated. Later, the modelled data were used for the cost estimation of the algae-based wastewater treatment plant. In the cost estimation model, excess sunlight was proposed to be used as a heat source, which may be exploited for heat requirements in the hydrothermal liquefaction of algal biomass and other processes in a bio-refinery. Most of the places do not have the data of diurnal variation of PAR or solar radiation. However, monthly average solar radiation is available for most of the places. Hence, a unique methodology was developed to simulate the diurnal solar radiation from the monthly average data using various fitting parameters obtained for the solar radiation to PAR conversion (vice versa) model. Later, simulated PAR/solar radiation for a place was used to estimate the cost of the algae-based wastewater treatment for that place. 


\section{Materials and Method}

\subsection{Instruments}

Solar radiation was measured using a Pyranometer located on the roof of the Mechanical Engineering Department (Indian Institute of Technology, Roorkee, India), whereas PAR readings were obtained using a LI-COR Light Meter (LI-250A) and a quantum sensor. Measured data were used to develop a model for PAR. PAR was recorded at a 1-h interval. Measurements were taken from 7 a.m. to 7 p.m. for a given day. Solar radiation data for Hyderabad, India; Sorkoto, Nigeria; and Aberystwyth, UK were obtained from the literature [26-28]. Solar radiation data for Jaipur was collected from a local body.

\subsection{PAR Modeling}

\subsubsection{Estimation of PAR from Solar Radiation}

Estimation of PAR can be obtained with the help of a set of modified equations given by $\mathrm{Hu}$ and Wang [29].

$$
\mathrm{PAR}=\mathrm{a} \rho_{\text {clear }}{ }^{\mathrm{b}} \cdot \mathrm{K}_{\mathrm{s}}^{\mathrm{c}} \mathrm{PAR}_{0} \cdot \sin (\mathrm{wt})
$$

PAR (extraterrestrial) is $39 \%$ of global solar radiation $\left(X_{0}\right.$ in watt $\left./ \mathrm{m}^{2}\right)$ and when this value is multiplied by 4.57 , PARo can be obtained $\left(\mu \mathrm{mol} / \mathrm{m}^{2} / \mathrm{s}\right)$.

$$
\begin{gathered}
\rho_{\text {clear }}=\frac{\text { PAR }_{\text {observed }}}{\text { PAR }_{\mathrm{O}}} \\
\mathrm{Ks}=\mathrm{X} / \mathrm{Xo}_{\mathrm{O}}
\end{gathered}
$$

$a, b, c$, and $w$ are the empirical coefficient, $t$ is the time (10 a.m. as 10, 1 p.m. as 13 etc.). $\mathrm{X}$ is the solar radiation and $\mathrm{X}_{0}$ is the extra-terrestrial solar radiation (ESR),

$$
\mathrm{Xo}_{\mathrm{o}}=\mathrm{I}_{\mathrm{sc}}\left[\sin \varphi \cdot \sin \delta+\left(\frac{24}{\pi}\right) \sin \left(\frac{24}{\pi}\right) \cdot \cos \varphi \cdot \cos \delta \cdot \cos \omega_{\mathrm{s}}\right]
$$

where $\mathrm{I}_{\mathrm{SC}}=1370 \mathrm{Watt} / \mathrm{m}^{2}, \varphi$ is the latitude of the location, $\delta$ stands for the solar declination, and $\omega_{\mathrm{S}}$ is the hour angle.

$$
\text { Solar declination, } \delta=23.45 * \sin \left[\frac{360}{365}(\mathrm{~d}+284)\right]
$$

where, $\mathrm{d}=$ Julian day, e.g., January $1(\mathrm{~d}=1)$.

Hour angle was measured using the traverse angle of the sun during sunrise to sunset.

Latitude of Roorkee, Jaipur, Hyderabad, Sorkoto, Aberystwyth, UK are as follows: $29.8543 \mathrm{~N}, 26.95 \mathrm{~N}, 17.3850 \mathrm{~N}, 12.55^{\prime} \mathrm{N}$, and $52.414 \mathrm{~N}$.

Solar radiation can be calculated from the measured PAR (Equations (1)-(5)).

\subsubsection{Estimation of Various Unknown Parameters for PAR Estimation Model}

In the present study, the model parameters were obtained through the application of optimization techniques with minimization of the sum of the square of residuals between measured and estimated PAR values, i.e.,

$$
\begin{gathered}
\text { Minimize } \sum(\text { Measured value }- \text { estimated value })^{2} \\
\text { Minimize } \sum\left(\mathrm{PAR}_{\text {measured }}-\mathrm{a} \cdot \rho_{\text {clear }} \mathrm{b} \cdot \mathrm{K}_{\mathrm{s}}^{\mathrm{c}} \mathrm{PAR}_{0} \sin (\mathrm{wt})\right)^{2}
\end{gathered}
$$

MATLAB (release 2019) optimization tool box (MathWorks Inc., Natick, MA, USA) was used for the minimization of error.

For the optimization in MATLAB, Equation (6) was used as the objective function to find out the parameters. Ks and $\rho_{\text {clear }}$ were obtained from the observed data (PAR and $\mathrm{PAR}_{0}, \mathrm{X}$ and $\mathrm{X}_{0}$ ) (Equations (2) and (3)). 


\subsection{Projection Model for PAR}

Solar radiation data obtained for other places contain only monthly average solar radiation. However, to estimate the heat production for a particular place from the excess solar radiation, which is not required for algae growth, require a diurnal variation of solar radiation. For simulating the diurnal variation of solar radiation or PAR, the following optimization routine was used (Equations (7)-(10)).

$$
\begin{aligned}
& \operatorname{maximize} \sum_{\mathrm{t}, \mathrm{i}=1}^{\mathrm{t}, \mathrm{i}=\mathrm{n}}\left[\text { PARobtained }-\mathrm{a} \cdot \rho_{(\mathrm{i}) \text { clear }}{ }^{\mathrm{b}} \cdot \mathrm{K}_{\mathrm{s}(\mathrm{i})}^{\mathrm{c}} \mathrm{PAR}_{0(\mathrm{i})} \sin (\mathrm{w} \mathrm{t})\right]^{2}+\sum_{\mathrm{i}=1}^{\mathrm{i}=\mathrm{n}}\left(\mathrm{SR}-\mathrm{K}_{\mathrm{s}(\mathrm{i})} * \mathrm{X}_{0 \mathrm{i}}\right)^{2} \\
& \text { subject to } \\
& {\left[\text { PARobtained }-\sum_{\mathrm{t}, \mathrm{i}=\mathrm{n}}^{\mathrm{t}, \mathrm{i}=\mathrm{n}} \frac{\left(\mathrm{a} * \rho_{(\mathrm{i}) \text { clear }}^{\mathrm{b}} \mathrm{b}\right) \mathrm{K}_{\mathrm{s}(\mathrm{i})}^{\mathrm{C}}}{\mathrm{n}} \mathrm{PAR}_{0(\mathrm{i})} \sin (\mathrm{wt})\right]^{2}+\left[\text { SRobtained }-\frac{\sum_{\mathrm{i}=1}^{\mathrm{i}=\mathrm{n}} \mathrm{K}_{\mathrm{s}(\mathrm{i}) * \mathrm{X}_{0}}}{\mathrm{n}}\right]^{2}=0} \\
& \mathrm{~K}_{\mathrm{s}(\mathrm{i}) * \mathrm{X}_{0}}-\mathrm{a} \cdot \rho_{(\mathrm{i}) \text { clear }}{ }^{\mathrm{b}} \cdot \mathrm{K}_{\mathrm{s}(\mathrm{i})}^{\mathrm{c}} \text { PAR }_{0(\mathrm{i})} \sin (\mathrm{wt}) \geq 0 \\
& \mathrm{X}_{0} \mathrm{~K}_{\mathrm{s}(\mathrm{i})}>\varepsilon
\end{aligned}
$$

where $\varepsilon>=0$.

Equations (8)-(10) are the constraints for the objective function. The first constraint (Equation (8)) ensures that the average of the estimated SR and PAR would satisfy the monthly average PAR or SR obtained from the literature. The other two constraints (Equations (9) and (10)) ensure that obtained PAR would never be greater than SR and SR would always be greater than or equal to zero during the simulated period ( $\varepsilon$ is a user defined value greater or equal to zero).

$\mathrm{Ks}(\min ) \leq \mathrm{Ks} \leq \mathrm{Ks}(\max ), \mathrm{a}(\min ) \leq \mathrm{a} \leq \mathrm{a}(\max ), \mathrm{b}(\min ) \leq \mathrm{b} \leq \mathrm{b}(\max )$ etc. SR is the average solar radiation that was collected from the literature. $X_{0}(\mathrm{i})$ and PARo(i) were the extraterrestrial solar radiation and extra-terrestrial PAR for a particular time (details of the calculation are given in under PAR modelling). The minimum and maximum values of pertinent parameters $\left(\mathrm{K}_{\mathrm{s}}, \mathrm{a}, \mathrm{b}, \mathrm{c}\right.$, etc.) were obtained from the modelling of PAR and SR for Roorkee, India. The minimization of objective function was used to obtain the various parameters $\left[a, b, c, K_{s}\right.$, pclear, and $\left.\omega\right]$ (Equation (7)). Later, these derived parameters were used to estimate the SR and PAR for each hour (Equations (1) and (3)). Equation (4) was used to estimate $\mathrm{X}_{0}$.

\subsection{Optimization of Cost of Algae Production Taking into Account Sunlight Distribution for Algae Growth and Heat Production}

The optimization routine developed for the cost minimization of algae dominated wastewater treatment included the cost of the following (i) cost of the trough for solar light harvesting and optical fiber cost used for sunlight harvesting and transport, (ii) land cost, (iii) cost of aeration, (v) cost of removing nutrients in the advanced biological nutrients removal process, (vi) selling price of algal biomass, (vii) equivalent selling price of heat generated from sun light, (viii) capital cost of construction of the algal pond and (ix) algae harvesting and drying cost. Data for the above-mentioned items were collected from various literature and given in Table 1. For the heat production estimation, for a designed sunlight intensity transfer in the algal reactor, the excess sunlight for a particular time was assumed to be converted to heat, whereas the lower sunlight intensity as compared to the designed value would be compensated by increasing the surface area of solar light harvesting trough. Hence, the designed sunlight intensity and sunlight distribution over a day would govern the area of sunlight trough (Equation (11)). 
Table 1. Various items used in optimization and their respective cost.

\begin{tabular}{ccc}
\hline ITEM & COST (INR) & SOURCE \\
\hline Land Cost & $1600 / \mathrm{sq} . \mathrm{ft}(\$ 21.62 / \mathrm{sq} . \mathrm{ft})$ & {$[30]$} \\
Cost of trough + optical fibre & 1231 USD for $4 \mathrm{~m}^{2}$ illumination area & Chong et al. [11] \\
Construction cost of algal pond & $0.60 \times 71 \times 8988 \mathrm{Q}^{0.71}$ & {$[31]$} \\
BNR cost & $16 / \mathrm{m}^{3}\left(\$ 0.22 / \mathrm{m}^{3}\right)$ & {$[32]$} \\
Biomass cost & $21 / \mathrm{kg}(\$ 0.28 / \mathrm{kg})$ & $\# \#$ \\
Aeration cost & $0.26 / \mathrm{m}^{3} / \mathrm{day}\left(\$ 0.003 / \mathrm{m}^{3} /\right.$ day $)$ & {$[33]$} \\
Cost of Heat Produced & $0.92 / \mathrm{MJ}[\$ 0.012 / \mathrm{MJ}]($ estimated taking & {$[10]$}
\end{tabular}

\#\# assume taking 30\% lipid in the biomass and selling price of lipid as 70 INR, land cost at Sorokoto and Aberystwyth were taken from following sources [31,32]; https://homes.mitula.com.ng/detalle/238612/161011958515007 2117/3/8/lands-sokoto?page=2\&pos=3\&t_sec=190\&t_or=2\&t_pvid=7b3a4c4a-bf3d-434f-b7c9-7c626d3ec178 [31] (accessed on 1 August 2021); https://www.onthemarket.com/details/8422968/ [32] (accessed on 1 August 2021).

The formulated objective function for the algae dominated wastewater treatment consists of the following items:

Land cost + cost of parabolic trough and cost of optical fiber + capital cost of building algal pond-BNR cost-aeration cost - cost of biomass produced - generated heat cost + cost of algae harvesting and drying.

Land cost: it is the cost of land required for constructing an algae-based treatment facility. Land requirement depends on the volume of water treated per day and the depth of the reactor. Hence, the total land cost $=$ flow $(\mathrm{Q}) *$ hydraulic retention time $(\mathrm{HRT}) *$ land cost/depth of the reactor $(\mathrm{H})$.

Cost of parabolic trough and cost of optical fiber: it is assumed that solar light falls on a square meter area could penetrate or cater $40 \mathrm{~cm}$ depth. Hence, the total area of the trough required $=$ flow $(\mathrm{Q}) *$ hydraulic retention time/0.4. It is assumed that the trough would be placed $3 \mathrm{~m}$ above the treatment facility. Hence, total length of the fiber required is $\mathrm{H}+3 \mathrm{~m}$, where $\mathrm{H}$ is the depth of the reactor. The sunlight harvesting and transfer equipment were modelled according to the device described in Chong et al. [11]. It is assumed that the cost of the equipment includes the cost of $3 \mathrm{~m}$ optical fiber. It is assumed that the cost of the equipment would be increased in proportion to the increment of fiber length above $3 \mathrm{~m}$. Other details about the harvesting equipment are given in Table 1. Hence, cost of trough $=((\mathrm{Q} * \mathrm{HRT}) / \mathrm{H} * \mathrm{H} / 0.4) *(3+\mathrm{H}) * 1231 * 71 /(4 *$ design period $* 3)$.

The construction cost of the algal pond and associated facilities were modelled according to the conventional wastewater treatment facility. Pertinent data for the same was taken from Friedler and Pisanty [33]. For estimating the capital cost of the algal pond, it was assumed that around $60 \%$ of the capital cost of municipal wastewater treatment would be required for algal pond. For municipal wastewater, around $30-40 \%$ of the total cost was accrued due to aeration and other electrochemical equipment. Accordingly, the cost of the algal pond $=0.60 * 71 * 8988 * \mathrm{Q}^{\wedge} 0.71$.

The algal pond facility provided enhanced nutrient removal efficiency, a credit for BNR cost was incorporated in the cost function. A similar approach was taken for aeration cost (credit was taken). Pertinent cost data are listed in Table 1.

$$
\mathrm{BNR} \text { and aeration cost }=-\mathrm{Q} * 16-\mathrm{Q} * 0.26
$$

Cost of biomass produced: Cost of the biomass depends on the biomass produced. In the algae-based wastewater treatment, the biomass productivity generally remained within $2 \mathrm{~g} / \mathrm{L} /$ day. Taking $2 \mathrm{~g} / \mathrm{L} /$ day biomass productivity Monod kinetic coefficients [K $=2$, $\mathrm{Km}=1000$ ] were obtained, which gave biomass productivity within $2 \mathrm{~g} / \mathrm{L} /$ day depending on the light intensity (I). Cost of biomass was assumed as 21 INR, assuming $30 \%$ lipid in the biomass [Table 1].

Hence, the biomass cost model takes the following form $=\left(\frac{\mathrm{K} * \mathrm{I}}{\mathrm{I}+\mathrm{K}_{\mathrm{m}}}\right) *(\mathrm{Q} * 21)$ where $\mathrm{I}=$ light intensity $\left(\mu \mathrm{mol} / \mathrm{m}^{2} / \mathrm{s}\right)$. 
Heat production cost: Excess sunlight that was not used for algal biomass production was assumed to be converted to heat. The total area of solar trough $=\mathrm{Q} * \mathrm{HRT} / 0.4$. Hence, heat produced $=(\mathrm{Q} * \mathrm{HRT} / 0.4) *(\mathrm{x}-\mathrm{p}) /(4.6 * 1000)$. Where $\mathrm{x}$ and $\mathrm{p}$ are the solar irradiance, and designed solar irradiance used for algal biomass production. $4.6 \times 1000$ was the conversion factor for changing the unit $\mu \mathrm{mol} / \mathrm{m}^{2} / \mathrm{s}$ to $\mathrm{Kwatt} / \mathrm{m}^{2}$. It is assumed that the duration of solar radiation in a day was approximately around $11 \mathrm{~h}$. Hence, $11 \times 3600$ multiplier was used to estimate heat energy produced all over the daytime. Accordingly, the total cost of produced heat $=\sum(((\mathrm{Q} * \mathrm{HRT}) / 0.4 * \mathrm{x}-$ $(\mathrm{Q} * \mathrm{HRT}) / 0.4 * \mathrm{p}) /(4.6 \times 1000)) *$ cost of natural gas $\times 11 \times 3600$, It is assumed that excess heat produced from sunlight would substitute natural gas, hence, cost of natural gas for producing an equal amount of heat was multiplied with excess heat produced.

Cost of algae harvesting and drying: cost of algae harvesting and drying includes algae harvesting using centrifuge and drying of algal biomass.

Cost of Algae harvesting = biomass produced $*$ energy required for centrifugation $*$ unit cost of electric energy.

Biomass produced $=((\mathrm{K} * \mathrm{I}) /(\mathrm{I}+\mathrm{Km})) *(\mathrm{Q})$, energy required for centrifugation $=$ $31 \mathrm{kwh} /$ dry ton of biomass [10], cost of electricity for $1 \mathrm{kwh}=6.5 \mathrm{INR}(\$ 0.09)$.

Drying energy requirement for water evaporation $=$ dry mass of algae produced $*$ energy required for increase the temperature of water from $30-100{ }^{\circ} \mathrm{C} *$ cost of the unit heat/ (water content $*$ efficiency of heat transfer $)=((\mathrm{K} * \mathrm{I}) /(\mathrm{I}+\mathrm{Km})) *(\mathrm{Q}) * 2.36 /(0.4 \times 0.8)$.

Hence, the cost of algae-based wastewater treatment would be the summation of the above terms, and the resulting objective function is given below (Equation (11)).

$$
\begin{aligned}
& \left(\frac{\mathrm{Q} * \mathrm{HRT}}{\mathrm{H}}\right) * \mathrm{LAND} \operatorname{COST}+\left(\frac{\mathrm{Q} * \mathrm{HRT}}{\mathrm{H}} * \frac{\mathrm{H}}{0.4}\right) *(3+\mathrm{H}) * 1231 * 71 /(4 * \text { design period } * 3)+0.60 * 71 * 8988 * \mathrm{Q}^{0.71}- \\
& (\mathrm{Q} * 16)-(\mathrm{Q} * 0.26)-\left(\frac{\mathrm{K} * \mathrm{I}}{\mathrm{I}+\mathrm{K}_{\mathrm{m}}}\right) *(\mathrm{Q} * 21)-\Sigma\left(\frac{\mathrm{Q} * \mathrm{HRT}}{0.4} * \frac{\mathrm{Q} * \mathrm{HRT}}{0.4} * \mathrm{p}\right) * \text { cost of natural gas } * 11 * 3600+\left(\frac{\mathrm{K} * \mathrm{I}}{\mathrm{I}+\mathrm{K}_{\mathrm{m}}}\right) *(\mathrm{Q}) *(31 * 6.5) / 1000 \\
& +\left(\frac{\mathrm{K} * \mathrm{I}}{\mathrm{I}+\mathrm{K}_{\mathrm{m}}}\right) *(\mathrm{Q}) * 2.36 /(0.4 * 0.8)
\end{aligned}
$$

In Equation (11),

$\mathrm{Q}=$ flow rate $\left(\mathrm{m}^{3} /\right.$ day $)$,

HRT $=$ Hydraulic retention time (day),

$\mathrm{H}=$ height of algal pond (meter),

$\mathrm{I}=$ solar light intensity used for algae growth (in $\mu \mathrm{mol} / \mathrm{m}^{2} / \mathrm{s}$ ),

$\mathrm{X}=$ solar light intensity for a particular time, $\mathrm{p}=$ solar light intensity used for algal growth $\left(\mu \mathrm{mol} / \mathrm{m}^{2} / \mathrm{s}\right)$.

For the optimization of the objective function, bound for height of the algal pond was taken as $0.4-10 \mathrm{~m}$, for the hydraulic retention time, it was 1-2 days, and for the flow, it was $1000-10,000 \mathrm{~m}^{3} /$ day.

Two scenarios were modelled, namely, conservative and optimistic. Details of each scenario are depicted in Table 2. In the optimistic scenario, the design period of several components was increased. The compound interest on capital was not considered as it would have a negligible share on the annuitized cost. For example, in India, most of the wastewater treatment plants are being built taking loans from various International development agencies which provided loan at very minimal interest rate (For example Asian Development Bank provides loan at an interest rate of $2 \%$ with a repayment time $30-40$ years). 
Table 2. Salient features of conventional and optimistic scenario.

\begin{tabular}{ccc}
\hline Items & Conventional & Optimistic \\
\hline land cost & 10 years & 10 years \\
algal pond * & 20 years & 30 years \\
solar trough * & 5 years & 10 years \\
optical fibers * & 5 years & 10 years \\
kinetic parameter $(\mathrm{k})$ & 2 & 3 \\
drying of biomass & included & not included \\
\hline
\end{tabular}

* design period (cost of equipment is same).

\section{Results and Discussion}

\subsection{Diurnal Patterns of Monthly Mean Hourly PAR Values}

PAR has a relationship with SR, and it varies during the observation period in Roorkee, Uttarakhand, India. Previous studies on solar light intensity modelling reported several relationships between PAR and SR. These models can be used for the estimation of PAR for the other places. Generally, the seasonal variations of PAR and SR follow solar declination angle, the latitude of the location, and the day of the year (Julian day). Trends in PAR are different for all seasons as it depends on the cloud cover also. The maximum monthly average PAR was observed (hourly average over a month) in June with an estimated average of $1427.58 \mu \mathrm{mol} \mathrm{s}-1 \mathrm{~m}^{-2}$. The minimum PAR was observed in February with an average value of $464 \mu \mathrm{mol} \mathrm{s}{ }^{-1} / \mathrm{m}^{2}$. PAR that is reaching the surface of Earth comprises of two portions; the first one is the factor that attenuates under clear skies ( $\rho$ clear), and the second one is the attenuation factor due to the cloud cover Ks (clearness index). Ks (clearness index) indicates the cloudiness that can be calculated from the ratio of SR and ESR. Cloudiness is correlated to the radiation duration since the least cloudy locations are also by default the sunniest location, while the cloudiest areas have the least sunny places. The low value of the Ks means the greater cloud cover or cloudiness and a higher value of Ks indicates less cloudiness in that location. Ks obtained in this study are higher in the winter months and lower in the autumn months (Table 3). Higher values of $\rho$ clear were estimated in winter, whereas the lower values were observed during autumn. The estimated values of KS varied from 0.22 to 0.39 (average value). Compared to the present study, $\mathrm{Hu}$ and Wang [29] reported a variation of Ks between 0.44 to 0.60 . However, their model is to some extent different from ours ( $\mathrm{w}$ and $\mathrm{t}$ are the two extra parameters incorporated in the present model).

Table 3. Month wise variation in fitting parameters.

\begin{tabular}{|c|c|c|c|c|c|c|c|}
\hline Month & $\begin{array}{c}\operatorname{PAR}(\text { Ave } \pm \text { Std.Dev) } \\
\mu \mathrm{mol} / \mathrm{m}^{2} / \mathrm{s}\end{array}$ & Ks (Ave \pm Std.Dev) & plear (Ave \pm Std.Dev) & a & $\mathbf{b}$ & c & $\mathbf{w}$ \\
\hline August & $221 \pm 225$ & $0.2 \pm 0.2$ & $0.2 \pm 0.2$ & $1.8 \pm 0.6$ & $0.6 \pm 0.3$ & $1.0 \pm 0.7$ & $1.8 \pm 0.8$ \\
\hline September & $586 \pm 599$ & $0.4 \pm 0.2$ & $0.4 \pm 0.3$ & $2.3 \pm 0.5$ & $0.9 \pm 0.6$ & $1.0 \pm 0.5$ & $1.4 \pm 0.6$ \\
\hline October & $182 \pm 111$ & $0.25 \pm 0.06$ & $0.4 \pm 0.3$ & $1.6 \pm 0.9$ & $0.9 \pm 0.3$ & $0.09 \pm 0.08$ & $0.7 \pm 0.9$ \\
\hline December & $400 \pm 453$ & $0.3 \pm 0.2$ & $0.6 \pm 0.3$ & $1.9 \pm 0.6$ & $1.2 \pm 0.8$ & $0.6 \pm 0.4$ & $1.4 \pm 0.8$ \\
\hline January & $523 \pm 398$ & $0.4 \pm 0.2$ & $0.5 \pm 0.3$ & $1.7 \pm 0.5$ & $0.6 \pm 0.2$ & $0.5 \pm 0.2$ & $0.4 \pm 0.3$ \\
\hline February & $496 \pm 496$ & $0.4 \pm 0.2$ & $0.4 \pm 0.3$ & $1.9 \pm 0.6$ & $1.0 \pm 0.8$ & $0.8 \pm 0.7$ & $1.7 \pm 0.7$ \\
\hline
\end{tabular}

\subsection{PAR (OBSERVED) vs. PAR (MODELED) and Solar Radiation (Observed) vs. Solar Radiation (Modelled)}

The diurnal variation of PAR for several months was also modelled and showed in Figures 1 and A3a-d (Appendix A). For some of the months of years (June, July, November, etc.) the PAR, SR modeling could not be conducted because of the non-availability of either solar irradiation or PAR data. Modelled values matched well with the measured values 
and indicated that PAR, SR modelling framework is efficient to predict the values of SR or PAR.

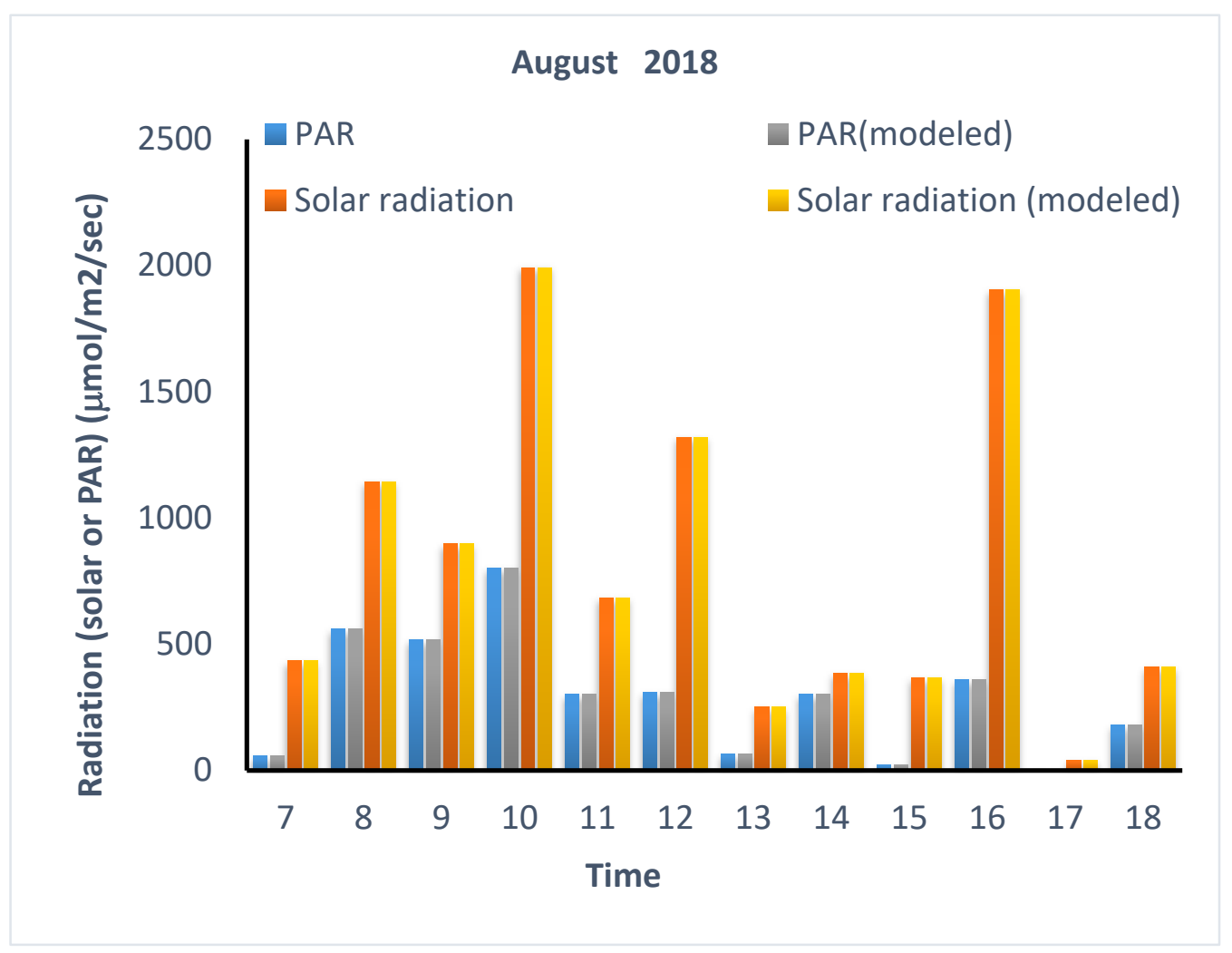

Figure 1. Comparison between observed and modeled data for PAR. Plot for other months are given in Appendix A.

The statistical results for the goodness of fit for modelled and observed values (PAR and SR) are presented in Table 4. The statistical parameters include Root Mean Square Error (RMSE) and the standard deviation (SD) ratio of measured and estimated PAR and SR. The RMSE provides the goodness of the fit between the modelled and observed value, whereas the ratio of standard deviation gives that both the data sets (modelled and observed) have a similar range of variation from their mean value. For Roorkee, root mean square error between the observed PAR, SR, and the modelled PAR and SR are less than $0.3 \%$ for each of the month. The ratios of standard deviation between measured vs. estimated values for each of the months were 1 . Hence, the model can simulate the individual data accurately and also able to capture the spread. Several other models are also being used to simulate solar radiation and PAR for a particular place. Depending on the modelling algorithms, the RMSE errors varied from as little as 3\% to more than $100 \%$ for some models. For example, Amrouche and Pivert [22] reported that ANN-based modelling could have very little error in the simulated data $(\sim 3 \%)$. Voyant et al. [34] showed that ANN augmented with a multivariate modeling scheme could decrease the RMSE errors to $0.5-1 \%$. These models also showed biases (either over predict or under predict the values). Compared to the models mentioned above, the empirical, physics-based model showed a higher degree of errors. For example, models developed by Liu et al. [35] showed more than $100 \%$ errors in the predicted values, whereas the empirical model developed by Ajayi et al. [25] showed RMSE within $11-100 \%$. These models also showed considerable biases in the estimation. 
Table 4. Root mean square error and standard deviation (measured/estimated) month wise (Roorkee).

\begin{tabular}{ccc}
\hline Months & RMSE (\%) & SD [(Observed)/SD(Modeled)] \\
\hline August & 0.06 & 1 \\
September & 0.16 & 1 \\
October & 0.06 & 1 \\
December & 0.14 & 1 \\
January & 0.18 & 1 \\
February & 0.25 & 1 \\
\hline
\end{tabular}

\subsection{PAR Prediction from Solar Radiation for Other Places}

After the measurement of PAR and modelling the same using the diurnal solar radiation data, a set of empirical parameters were obtained. However, for most of the places in India and other places in the world, only the monthly average value of solar radiation was available. However, for implementing algae-based wastewater treatment in which sunlight would be used for its growth and excess sunlight would be used for generating heat, one needs to have a diurnal variation of sunlight. Therefore, an attempt has been made in this study to simulate the diurnal variation of PAR and solar radiation from monthly average solar radiation data. For this purpose, three places were chosen, Jaipur, India, Sorkoto, Nigeria; and Aberystwyth, UK $[27,28,36]$. However, before simulating the diurnal variation of PAR, simulation of monthly average PAR from solar radiation was obtained. Monthly average solar radiation data sets were obtained, and then the developed model (Equations (1)-(6)) was used to estimate the PAR and SR with the help of empirical parameters obtained for Roorkee.

\subsection{Calibration of a Model to Simulate the Diurnal Variation of PAR from the Monthly Average Solar Radiation}

After modelling the monthly average PAR from monthly average solar radiation, diurnal variation of PAR and SR were modeled using Equations (7)-(10). For Jaipur, hourly PAR and solar radiation (SR) was estimated from the average monthly PAR and SR (Figure 2). For other places, the simulated values are given in the Appendix A. In this model, it is assumed that the average of the diurnal variation of PAR or SR would comply with the PAR or SR obtained from the literature. The model tried to maximize the variance between the average of the SR or PAR and the estimated one (Equations (7)-(10)). It is also assumed that the empirical parameters such as Ks, pclear, and $t$ would vary for each of the estimated data points. Due to these features in the model, the diurnal variation of PAR and SR showed random patterns. In most months, the maximum PAR or SR occurred between 12 p.m. to 2 p.m. Measured PAR (some of the data are shown in the Appendix A) also showed some irregularities; however, such irregularities are not as dramatic as compared to the simulated one. As our main goal is to develop a diurnal variation, the random pattern in the variation would not affect the outcome of the cost optimization routine. However, if one wants, a modification of the present algorithm could also simulate a smooth pattern of diurnal variation of SR and PAR. Simulating the smooth pattern of the diurnal variation require a set of constant parameters (Ks, pclear, a, b, c and w), which were estimated using optimization routine and used for simulating the SR and PAR for a particular month (Figure A5 in Appendix A). For a smooth variation of SR or PAR, the maximum intensity used to occur between 11-12 p.m. The maximum intensity observed in the smooth profile was lower than the one observed in the irregular profile. Diurnal variation of weather data could also be implemented (cloudiness index) and the present scheme to simulate a more realistic diurnal variation of PAR and SR. 


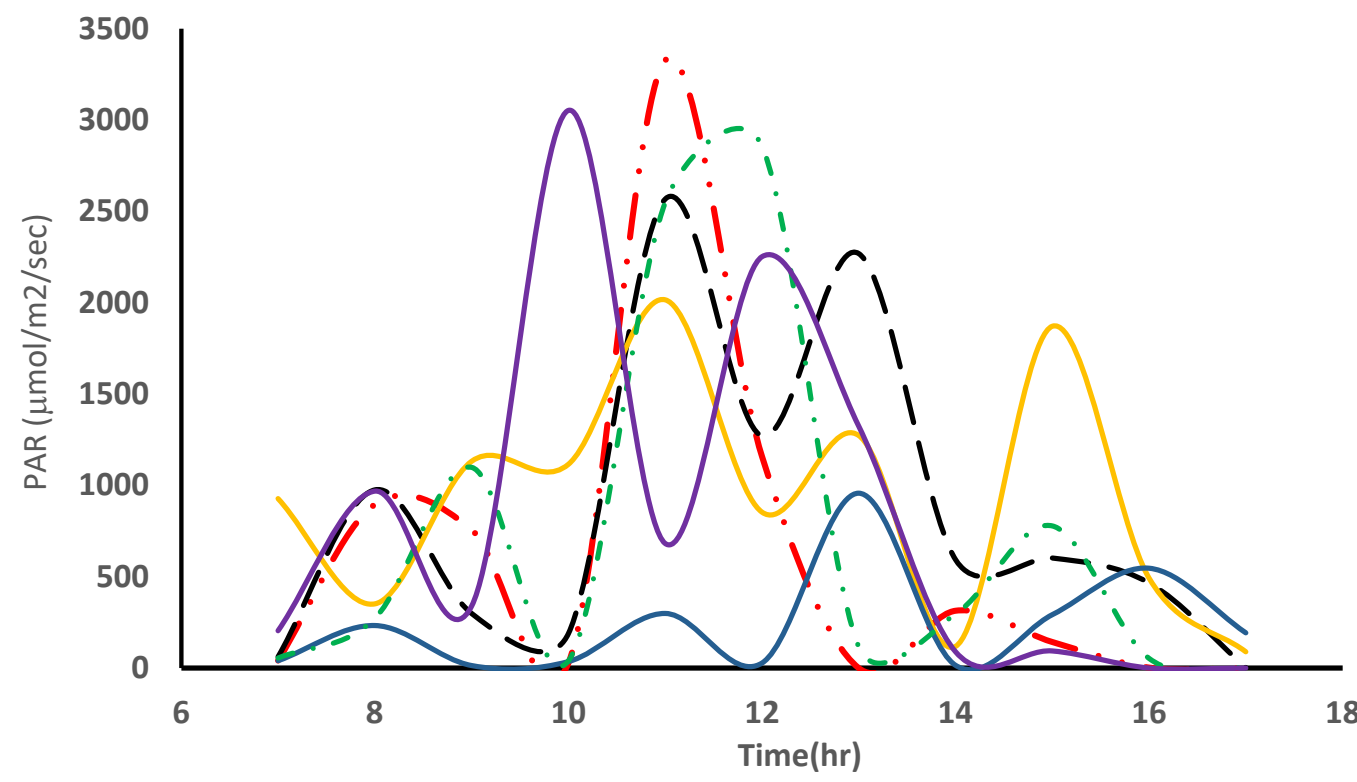

- Jan - March May - July _- Oct Dec

(a)

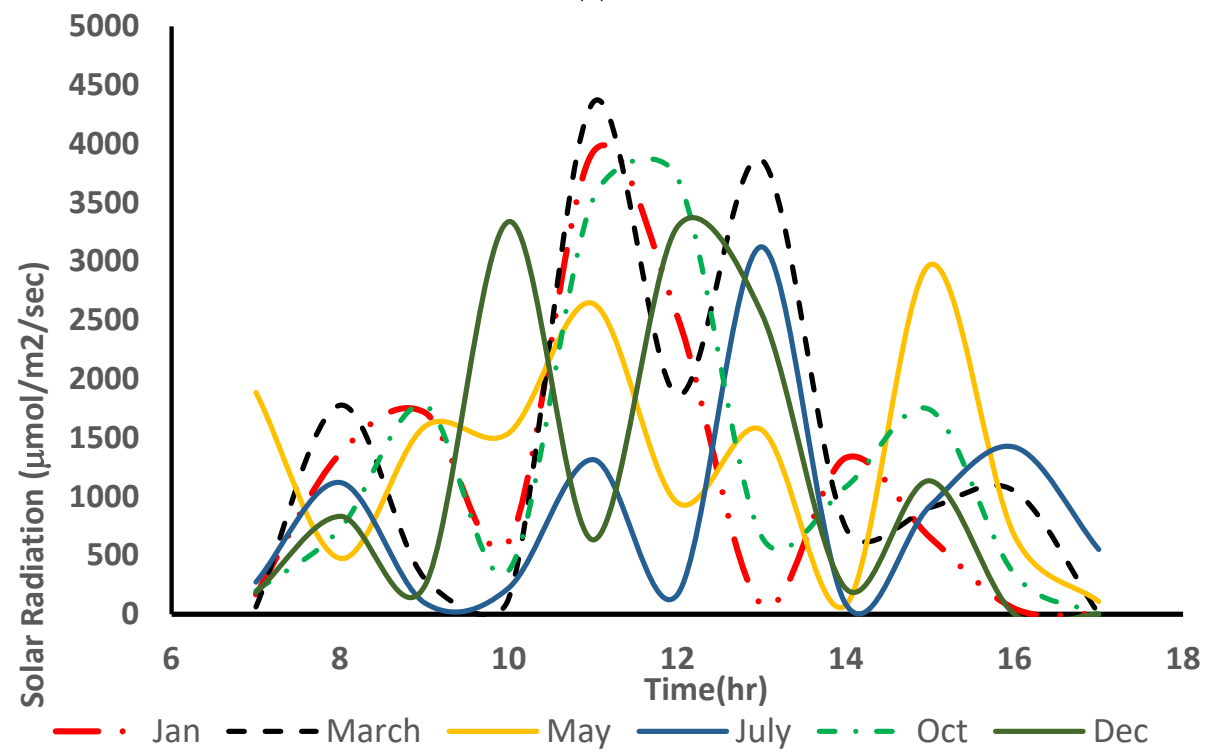

(b)

Figure 2. Hourly projection of (a) PAR and (b) solar radiation for Jaipur (month wise). Simulations for all the months are not shown.

\subsection{Cost of Solar Heating Integrated Algae-Based Wastewater Treatment}

Cost optimization of the solar heating integrated algae-based wastewater treatment was carried out using Equation (11). For this purpose, simulated solar radiation and PAR for Jaipur, Sorkoto Aberystwyth, and Hyderabad were used. Month-wise variation of cost of the treatment (INR $/ \mathrm{m}^{3}$ wastewater treated) was estimated and shown in Figures 3 and 4.

Jaipur, India: The cost of the treatment $\left(\mathrm{INR} / \mathrm{m}^{3}\right.$ ) for Jaipur varied from 9 to 18 (per $\mathrm{m}^{3}$ wastewater treated) in the conservative scenario (\$0.12-\$0.24). However, if one considered an increase in the design period (opportunistic scenario), the wastewater treatment unit registered profit yearly. The cost of the treatment (per $\mathrm{m}^{3}$ wastewater treated/day) varied 
from -17 to -26 INR (profit) (Figure 3a) ( $-\$ 0.23--\$ 0.35)$. The optimum design parameters (flow, HRT, Depth of the pond, and irradiance used for algal growth) obtained from the optimization exercise remained constant throughout the year (except irradiance). In the optimistic scenario, the values of most of the design variables remained the same as compared to the conservative scenario, except for the depth of the pond. The depth of the pond was increased from $0.7 \mathrm{~m}$ in the conservative scenario to $1 \mathrm{~m}$ in the optimistic scenario. The major cost of the treatment was incurred due to the solar light harvesting and transport device. The cost of the unit varied from 7000 INR to 14000 INR depending on the scenario (\$95-\$189). The major income was registered by biomass selling and incorporating the biological nutrients removal in the wastewater treatment unit (Figure 4a). The capital cost of constructing such a unit for treating $1000 \mathrm{~m} 3$ /day in Jaipur could be varied between 11 to 14 crores ( $\$ 1.5$ million- $\$ 1.9$ million). $47-62 \%$ of this cost is incurred by the solar light-harvesting unit. The capital cost of the solar light-harvesting unit can be recovered by 2 to 4 years from the heat production.

Sorkoto, Nigeria: The cost of the wastewater treatment in Sorkoto showed a similar trend as in Jaipur. However, the cost of the treatment is lower than that estimated in Jaipur. In the conservative scenario, the cost of the treatment varied from 3 INR to 7 INR (per $\mathrm{m}^{3}$ wastewater treated per day). In contrast, in the optimistic scenario, the treatment unit registered profit, and profit varied from 19 INR to 27 INR for treating $1 \mathrm{~m}^{3}$ wastewater/day (Figure 3b). It was also observed that in the optimistic scenario, an increase in wastewater flow from $1000 \mathrm{~m}^{3}$ (conventional scenario) to $10,000 \mathrm{~m}^{3}$ was observed. The capital cost of the unit (1000 $\mathrm{m}^{3} /$ day capacity) was estimated to be varied between $11-14$ crores (\$1.5 million-1.9 million) depending on the scenario.

Aberystwyth, UK: In Aberystwyth, solar radiation was low all over the year. Hence, for the growth of the microalgae, it was noticed that the intensity of the solar radiation for $6 \mathrm{~m}^{2}$ should be concentrated to $1 \mathrm{~m}^{2}$ area for the growth of microalgae and the treatment of wastewater. However, even after increasing the area of the solar harvesting device, the whole treatment unit could not make a profit even in the optimistic scenario. The cost of the treatment in the conventional scenario varied from 126-187 INR (\$1.70-\$2.53), which was one order magnitude higher as compared to other places studied in this study. In the optimistic scenario, the cost of the treatment could be reduced to 16 INR (\$0.22) for one or two months (Figure 3c). As the treatment unit required a larger area for concentrating sunlight and harvesting, the major cost of the treatment was accrued by the sunlight harvesting and transport device, and the cost is more than 4-5 times higher for treating the same amount of wastewater (Figure $4 \mathrm{c}$ ). $82 \%$ of the capital cost $\left(1000 \mathrm{~m}^{3} /\right.$ day unit) was consumed by the solar light-harvesting unit. The cost associated with the device varied from $37 \mathrm{~K}$ to $74 \mathrm{~K}$ (INR), whereas in Jaipur or in Sorkoto, similar equipment consumed no more than $7 \mathrm{~K}$ to $13 \mathrm{~K}$ (Figure 4). The cost of the solar light harvesting devices can be recovered within 4 to 7 years depending on the scenario (optimistic vs. conservative scenario). 

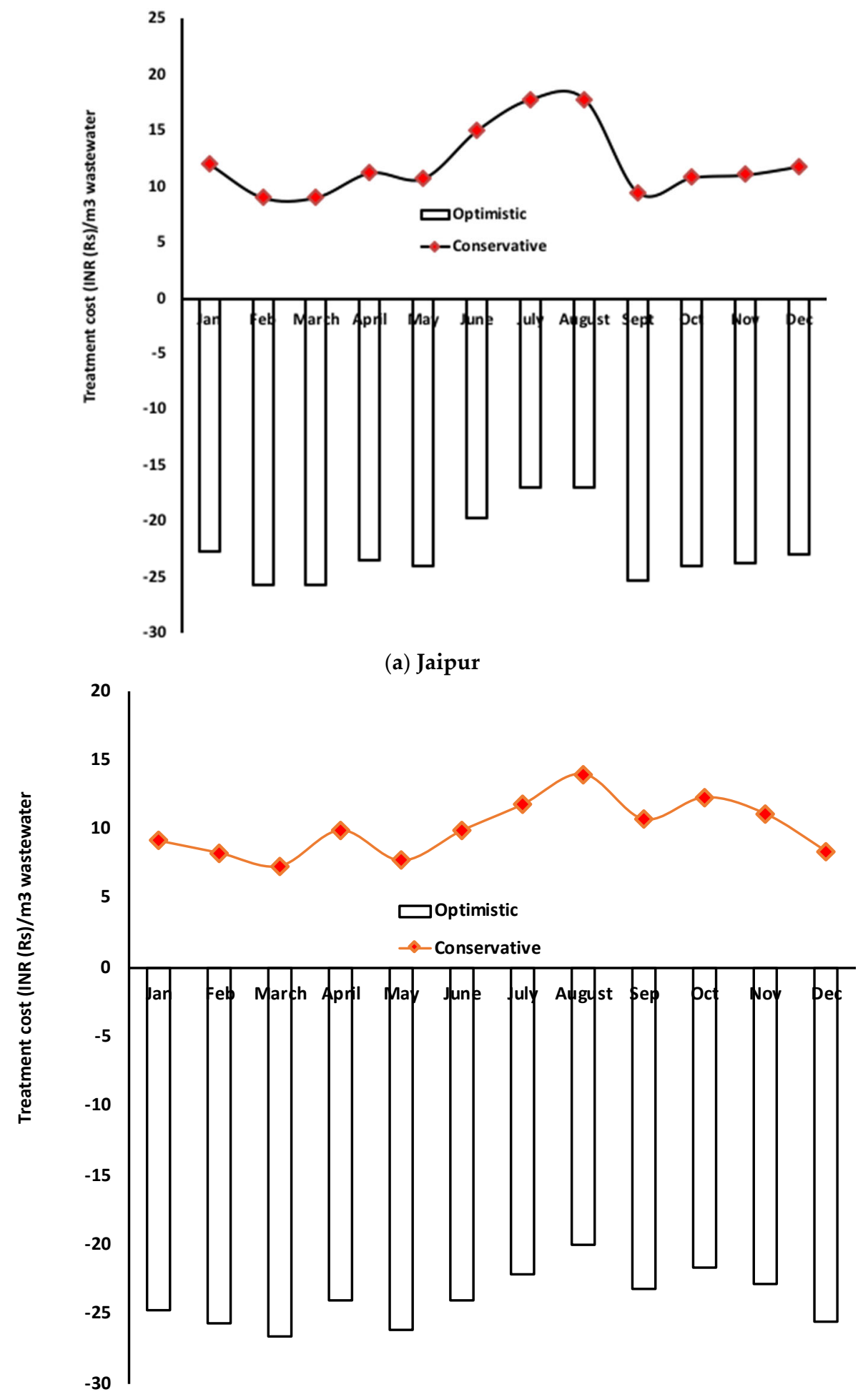

(b) Sorkoto

Figure 3. Cont. 


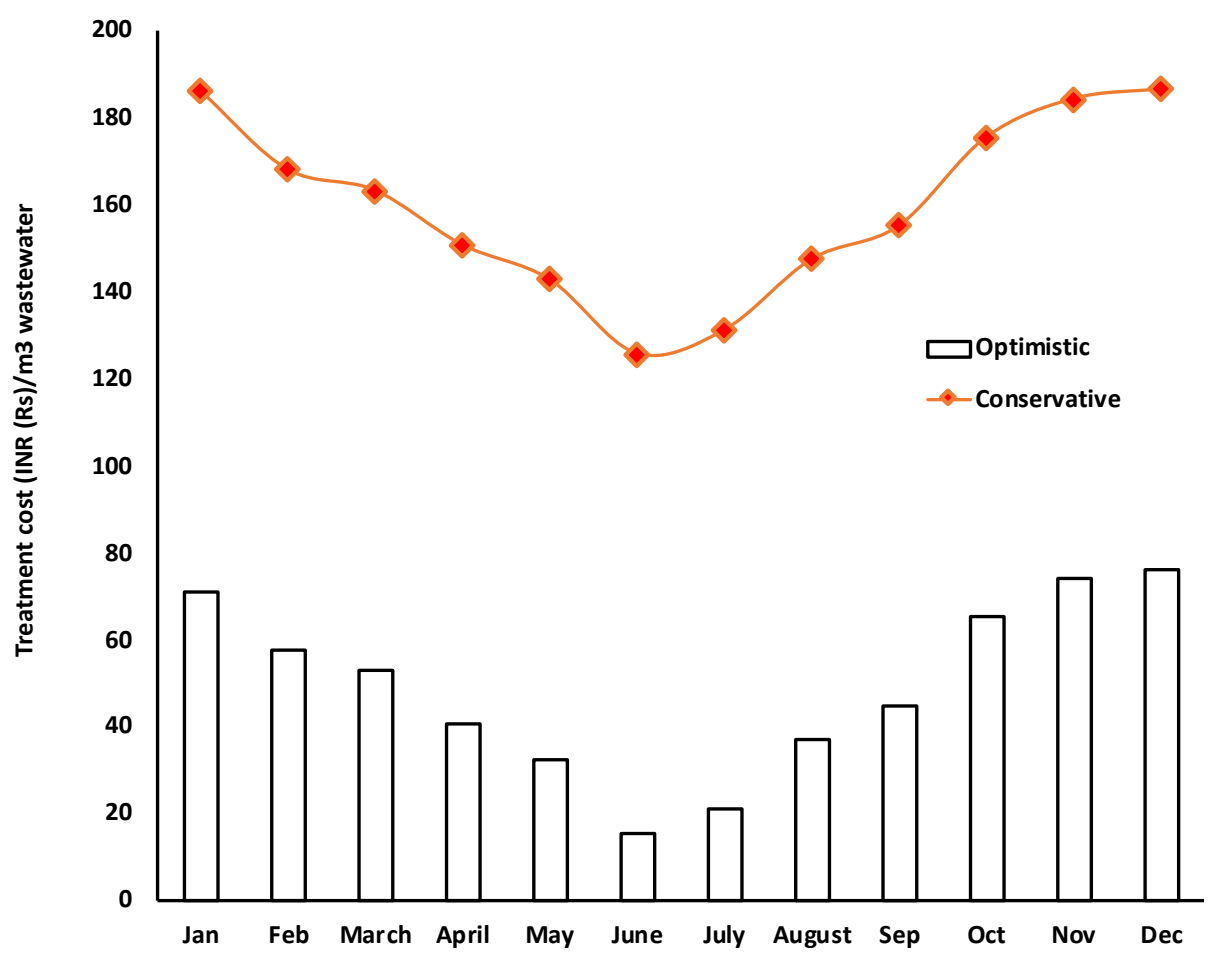

(c) Aberystwyth

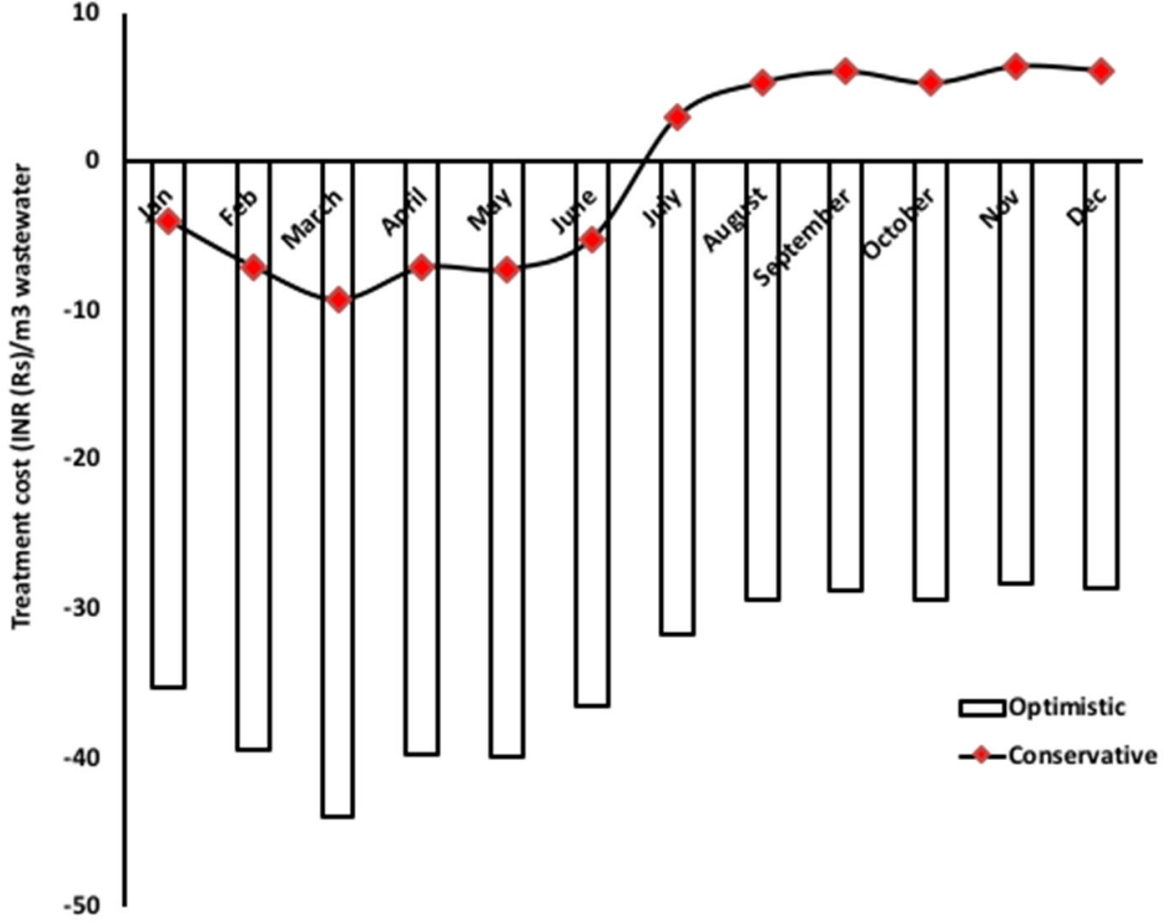

(d) Hyderabad

Figure 3. Month wise variation of cost of wastewater treatment and heat production system in (a) Jaipur, (b) Sorkoto, (c) Aberystwyth and (d) Hyderabad. 


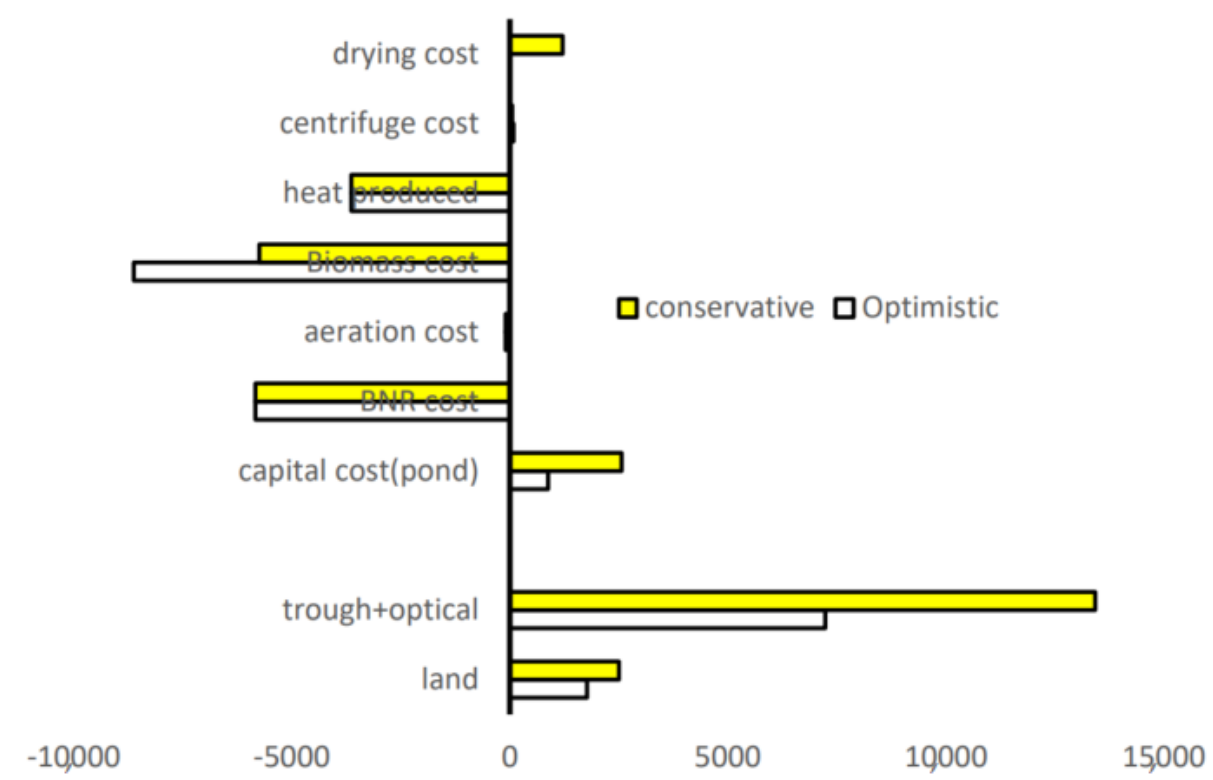

Cost of Wastewater treatment for various items ( $\mathrm{Rs} / \mathrm{m} 3$ wastewater treated/year)

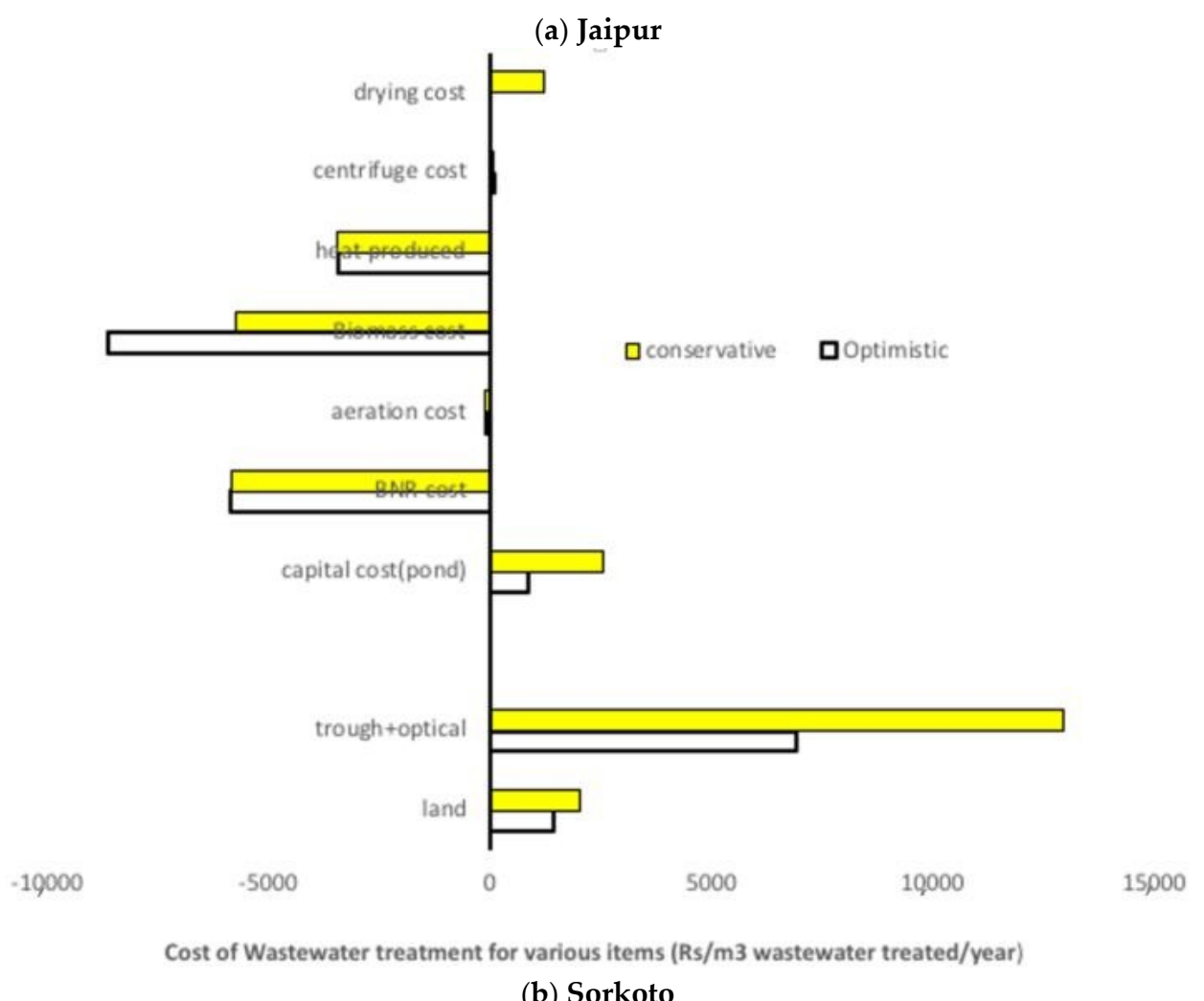

(b) Sorkoto

Figure 4. Cont. 


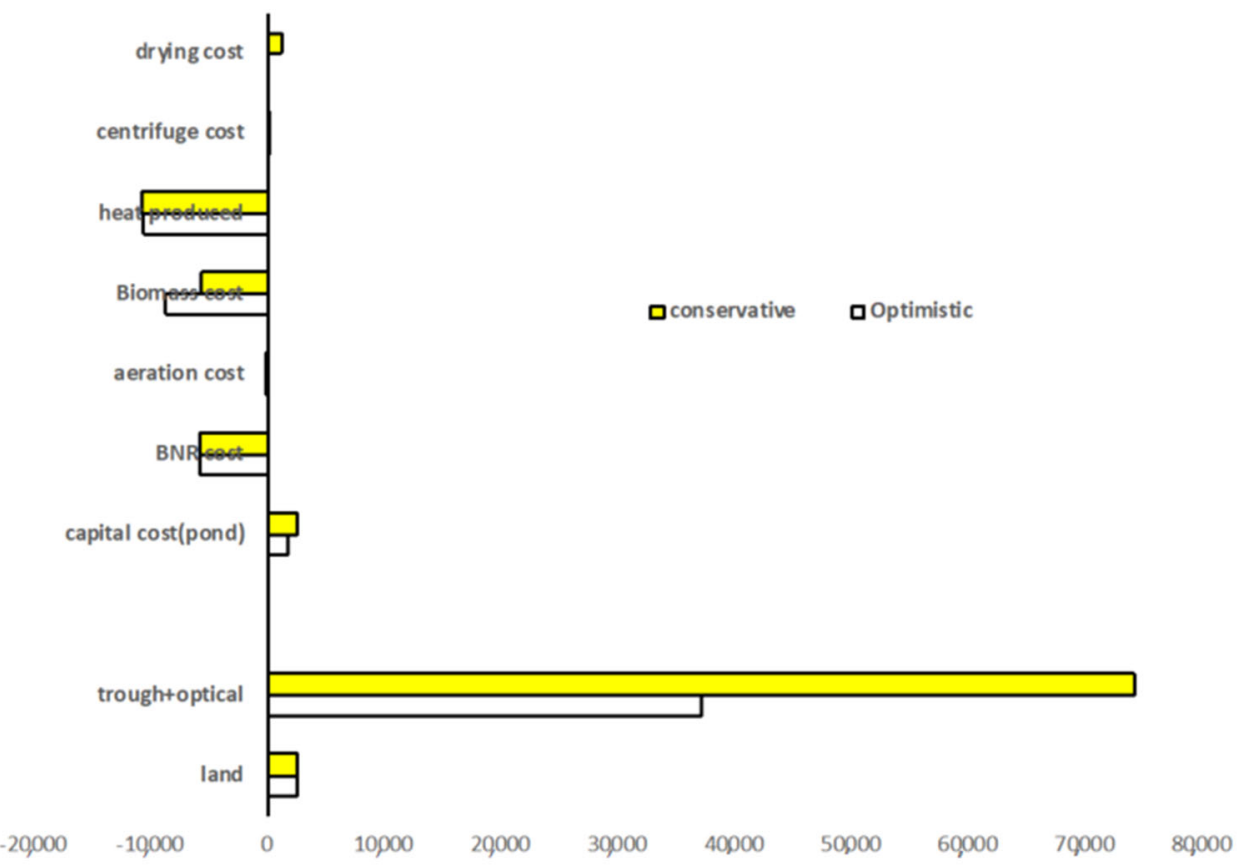

Cost of Wastewater treatment for various items (Rs/m3 wastewater treated/year)

(c) Aberystwyth

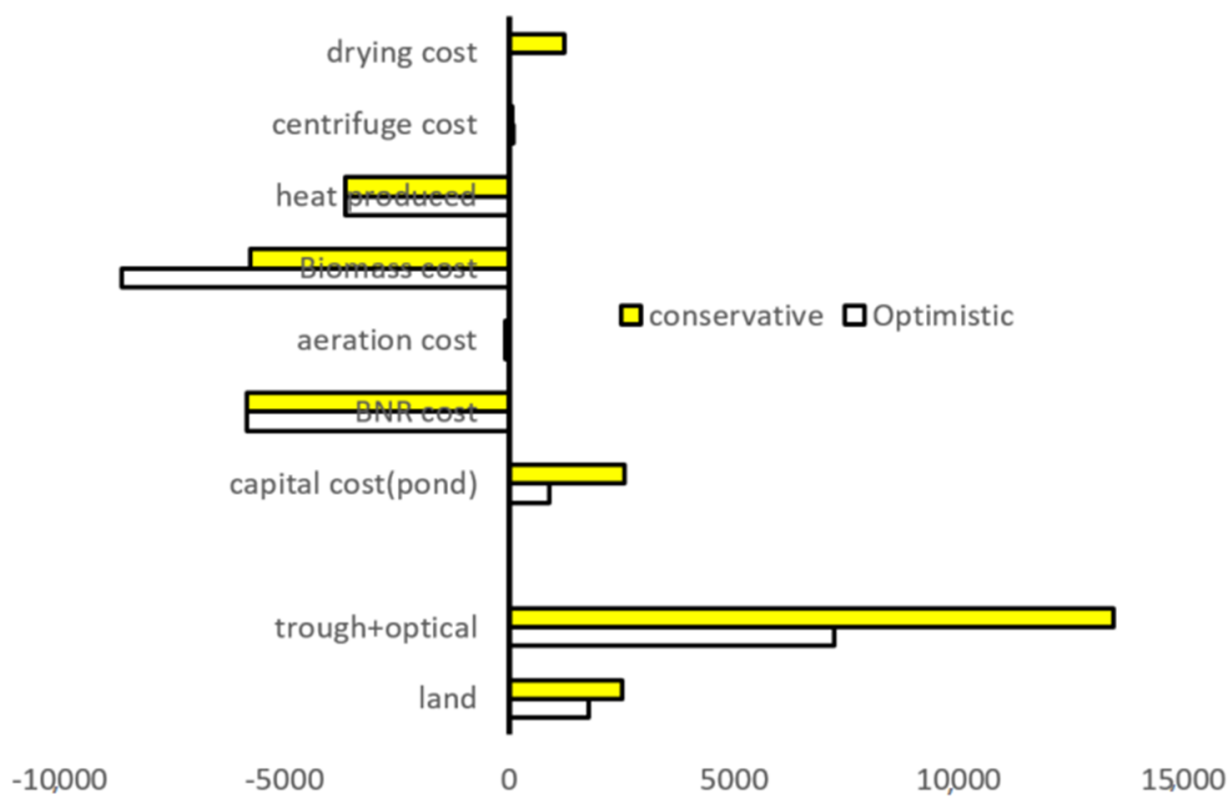

Cost of Wastewater treatment for various items (Rs/m3 wastewater treated/year)

(d) Hyderabad

Figure 4. Cost of various component of algae-based wastewater treatment in (a) Jaipur, (b) Sorkoto, (c) Aberystwyth and (d) Hyderabad.

Hyderabad, India: A similar exercise was also carried out for Hyderabad. Optimal parameters were similar as obtained for Jaipur. However, the obtained flow increased to $\sim 10,000 \mathrm{~m}^{3} /$ day. The treatment unit showed profit even in the conservative scenario. However, profit was registered for six months of the year. The cost of the treatment (INR, 
Rs) varied from 6 to -9 (profit). In the optimistic scenario, the unit registered profit all over the year and profit (INR, Rs) varied from -28 to -44 (per $\mathrm{m}^{3}$ of wastewater treated) (Figure 3d). The capital cost of constructing such a unit for $1000 \mathrm{~m}^{3} /$ day capacity was estimated for Hyderabad as 11 crores (\$1.5 million). Contrary to Jaipur, the capital cost did not vary for a conventional and optimistic scenario. The capital cost of solar harvesting devices can be recovered within two years by selling produced heat.

Several studies have also been carried out for algae-based biofuel production with or without integrating the solar light-harvesting system $[12,37,38]$. According to these studies, the integration of sunlight harvesting and waste nutrients was the key to the economic feasibility of the treatment unit. Some of these units, even though energetically favorable, are not economically viable [37]. For example, the net energy ratio reported by Hognon et al. [37] varied between 0.7-1.1, comparable with other studies, which used waste nutrients for biofuel production [39-42]. However, economic analysis carried out by Hognon et al. [37] reported that the cost of the produced biofuel would be around 195 INR. Davis et al. [38] reported that the minimum cost of algal biomass production was 35 INR. If one considers even $30 \%$ lipid in the biomass, the cost of the produced biofuel can be as high as $116 \mathrm{INR} / \mathrm{L}$. The major cost of algal biomass production, as reported by Davis et al. [38] was because of culture media and cultivation. However, Acien et al. [43] reported the major cost of algal biomass production was incurred by labour and capital cost. The cost of biomass production $(€ 69 / \mathrm{kg})$ was also much higher than the cost reported by Davis et al. [38].

Contrary to the above finding, Delrue and his coworkers estimated that the cost of producing biodiesel could be kept below 2 USD/L [44]. Integrating waste nutrients and sunlight can reduce the cost of biofuel production to 80 INR (\$1.08) [12]. Considering the cost offset due to avoidance of aeration and cost of tertiary wastewater treatment, the whole unit as described in this study can be made economically viable except in Aberystwyth, UK. For evaluating the cost comparison, the item-wise cost for treating wastewater was also evaluated in this study (Figure 4). According to the data obtained in this study, it was observed that the major cost of the treatment was incurred by sunlight harvesting and transport device. The annuitized cost of this device was atleast 7000 INR and can be as high as 74,000 INR. However, increasing the design period of optical fibre from 5 years to 10 years could reduce the annuitized cost to 37,000 INR. Hence, the very high cost of solar lightharvesting devices and low sunlight intensity could not make the whole unit profitable in Aberystwyth. It was observed that in all the places, the maximum biomass production occurs at $600 \mu \mathrm{mol} / \mathrm{m}^{2} / \mathrm{s}$. The concentration of biomass was around $750 \mathrm{mg} / \mathrm{L} / \mathrm{d}$, which was on the higher side as compared to the present algae production data available using wastewater [45,46]. However, it is possible to develop algae-based wastewater treatment technology using special algal strains, which could grow in low light intensity. Most of the algae-based wastewater treatment studies showed the growth of algae in light intensity, not more than $250 \mu \mathrm{mol} / \mathrm{m}^{2} / \mathrm{s} \mathrm{[46].} \mathrm{Hence,} \mathrm{there} \mathrm{is} \mathrm{a} \mathrm{considerable} \mathrm{scope} \mathrm{to} \mathrm{reduce} \mathrm{the}$ cost of wastewater treatment in Aberystwyth. For this purpose, another few simulations were carried out taking several fixed solar radiations $\left(100-250 \mu \mathrm{mol} / \mathrm{m}^{2} / \mathrm{s}\right)$ for algal growth, whereas biomass productivity varied between $(750-2000 \mathrm{mg} / \mathrm{L} /$ day). From a perusal of these simulations, it was observed that if one considered $100 \mu \mathrm{mol} / \mathrm{m}^{2} / \mathrm{s}$ as solar radiation and corresponding algal growth as $2000 \mathrm{mg} / \mathrm{L} /$ day, the whole facility could provide profit during June and July month for the opportunistic scenario. Hence, in the regions like Aberystwyth, UK, where solar radiation was low, increasing the biomass productivity in the low light setting would not be sufficient. The biomass productivity was also high, corresponding to the current algal biomass productivity observed in the raceway ponds. However, considering the better distribution of solar radiation, it is possible to improve biomass productivity $[7,8,47]$. Optical fiber-based light distribution system improved the biomass productivity by $38-43 \%$ and could reach biomass productivity as high as $2.53 \mathrm{~g} / \mathrm{L} /$ day. However, the above-mentioned data were collected from facilities where synthetic media was used. Hence, to facilitate the implementation of the facility proposed in this study, one needs to improve the economics of solar radiation harvesting and distribution equipment. For understanding the sensitivity 
of this equipment on the cost of the treatment, it was assumed that the design period was increased further to 15 years. In that case, when the design period was 15 years, the facility could register profit for most of the months of the year.

Cost of the various components of the proposed facility: As compared to the present study, John and Laxmanan [48] estimated that the cost of the solar trough would be around $200-500 \mathrm{INR} / \mathrm{m}^{2}$ depending on the size of the trough. However, they did not consider the cost of the tracking devices, absorbers etc. in their calculation. The annuitized cost for constructing the algal pond estimated in this study varied from 900-2600 for treating $1 \mathrm{~m}^{3}$ wastewater. As reported in the literature, the capital cost of algal pond construction (annuitized) varied from 32-300,000 INR [38,43]. The cost of biomass production was assumed at 21 INR in this study; however, the cost of stand-alone algal biomass production using artificial media could be as high as $1639 / \mathrm{kg}$ [38]. The selling price of heat obtained in this study and reported in literature match well with each other, and heat production provided profit in the range of $3500-11,000$ (INR) depending on the location of the study (Figure 4). The heat production provided the maximum revenue in Hyderabad and Aberystwyth, whereas biomass provided almost similar revenue in all the places. A perusal of the breakdown of cost obtained from the analysis also depicted drying cost, and centrifugal cost (operational cost) contributed little to the overall cost of the treatment. However, energy analysis studies depicted that algal biomass harvesting is one of the bottlenecks of algal biomass production [49]. Hence, it can be deduced that even though the energy demand is very high in the algae harvesting and drying process, the cost of energy and harvesting would not contribute much to the overall cost of the proposed algae-based wastewater treatment.

Several other studies also reported the advantages and disadvantages of solar energy in biomass drying, waste remediation, and in renewable energy production [10,50-53]. These studies showed that depending on the type of uses and location of application affect the cost of energy derived from sunlight. For example, Safei et al. [50] argued that a solar concentrator for cogeneration of heat in place of natural gas could be economically viable in some parts of Portugal. However, the application of solar PV was not economically viable in Portugal, China and even in Saudi Arabia [50-53]. Poblet and Painemal [10] observed that solar concentrator-based heat drying of sludge could improve the energy efficiency as compared to the conventional heat drying of sludge. Hence, it can be deduced that the heat production from sunlight is the most economically viable method. A similar observation was also observed in the present study. Most of the revenue in the study was gathered from heat production. However, the present simulation of diurnal variation of solar radiation and the associated heat production model did not include the quality of heat production. Generally, waste heat with a temperature range of $60-80^{\circ} \mathrm{C}$ is available in a considerable amount in most of the petrochemical or chemical industries [54]. As the temperature required for drying biomass seldom reach above $100{ }^{\circ} \mathrm{C}$, hence, such a heat source can be available without burning fuels. However, a heat source, which has a temperature above $300{ }^{\circ} \mathrm{C}$, which is required for the thermochemical treatment, needs to be obtained by burning fuels [55].

Hence, if one considers such intricate details, depending on the available waste heat source, the production of high-temperature heat can be increased. Some studies on solar heat concentrators reported that solar light intensity also affected the temperature obtained at the concentrating area. Generally, air, water, or oil are being used for harvesting the concentrated heat. If one tried to increase the temperature of the heat harvesting fluids by controlling the flow of fluids, the heat transfer efficiency was also changed [56].

The present research is primarily carried out to simulate the integration of solar energy for algae-based wastewater treatment and for simulating solar irradiance where the diurnal variation of solar radiation is not available. The model can be applied to places to estimate the algal biofuel production potential using available municipal wastewater and simulated solar radiation.

\section{Conclusions}

Developed PAR, SR estimation model, showed that observed vs. modeled values match well and had a very low root mean square error $(\sim 0.3 \%)$. The algae-based wastewater 
treatment integrated with sunlight harvesting and heating could be profitable for most of the month in a year where the sunlight intensity is high. The major cost of the treatment was incurred by the sunlight harvesting device. Biomass and heat production provided the maximum profit for the unit. The proposed sunlight integrated wastewater treatment method can be a profitable method of treating wastewater and producing biomass in places where sunlight intensity is high. The methodology depicted in this manuscript provides a robust guideline for estimating the feasibility of an algae-based wastewater treatment unit where a diurnal variation of sunlight was not available. The capital cost of the unit varied between 11-44 crores (\$1.5 million-5.9 million) depending on the place of the construction. The major fraction of the capital cost was consumed by the solar light-harvesting unit.

Author Contributions: Conceptualization, R.C. and S.K.D.; methodology, R.C. and S.K.D.; software, S.V. and R.C.; validation, S.V., R.C. and M.J.F.; formal analysis, S.V. and R.C.; investigation, S.V. and R.C.; resources, R.C.; data curation, S.V and R.C.; writing-original draft preparation, S.V. and R.C.; writing-review and editing, R.C., S.K.D., M.J.F. and G.L.; visualization, R.C., S.V. and G.L.; supervision, R.C.; project administration, R.C.; funding acquisition, R.C. All authors have read and agreed to the published version of the manuscript.

Funding: (Funding agency: Dept. of Biotechnology (DBT-893-CED)), Govt. of India. Saumya Verma received fellowship for her master degree from the Ministry of Human Resources and Development (MHRD), Govt. of India.

Institutional Review Board Statement: Not applicable.

Informed Consent Statement: Not applicable.

Data Availability Statement: Not applicable.

Conflicts of Interest: The authors declare no conflict of interest.

\section{Appendix A}

$1 \mathrm{USD}(\$)=74$ (RS, INR) [Conversion factor USD (\$) to Indian currency (Rs)].

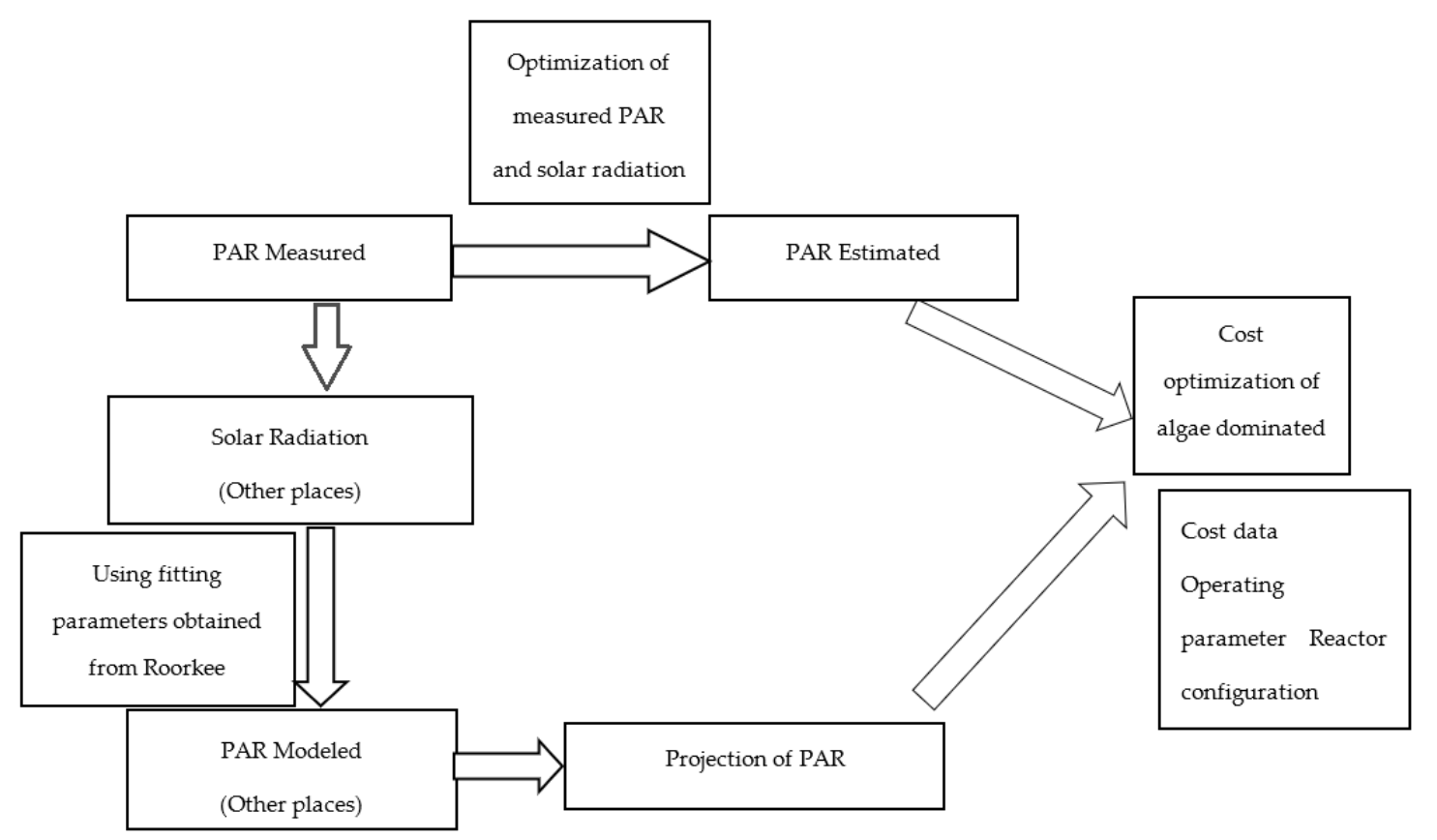

Figure A1. Schematic representation of various methodology used in this study. 


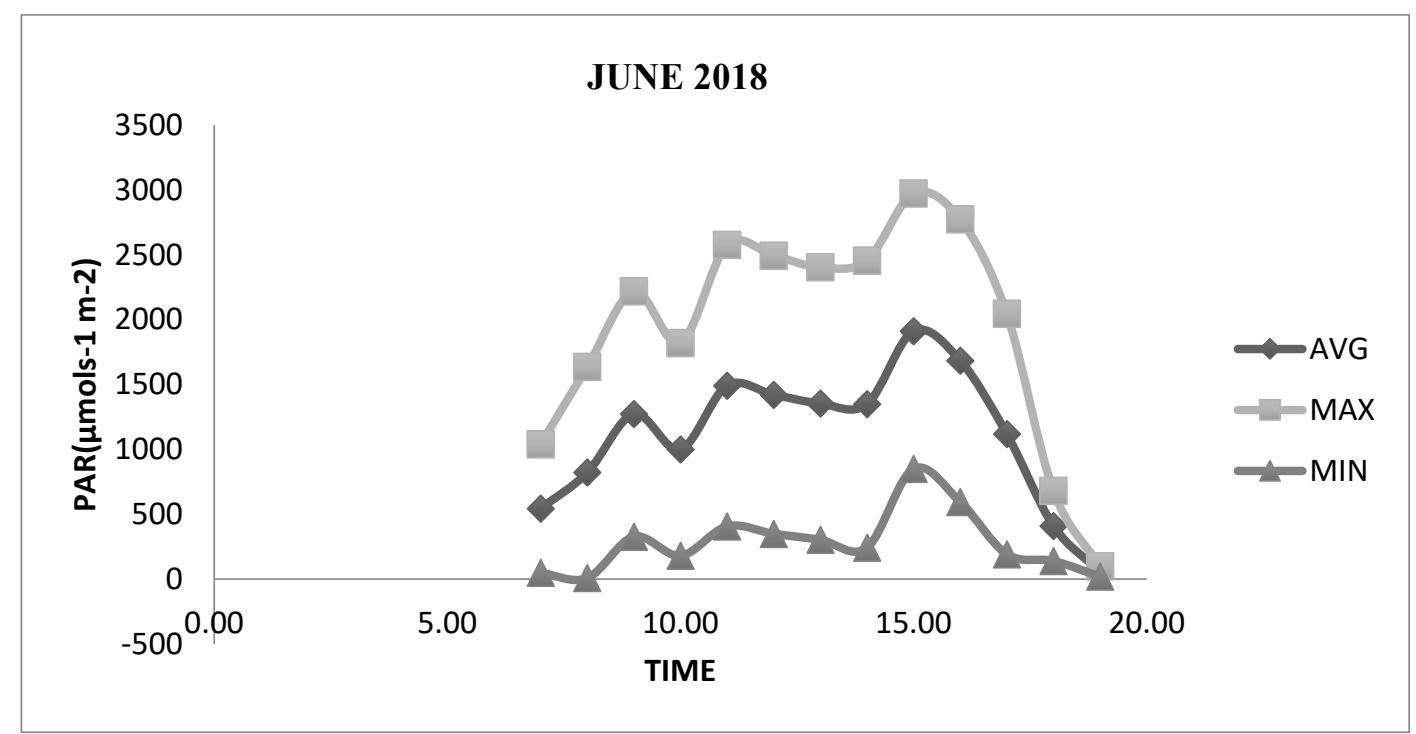

(a)

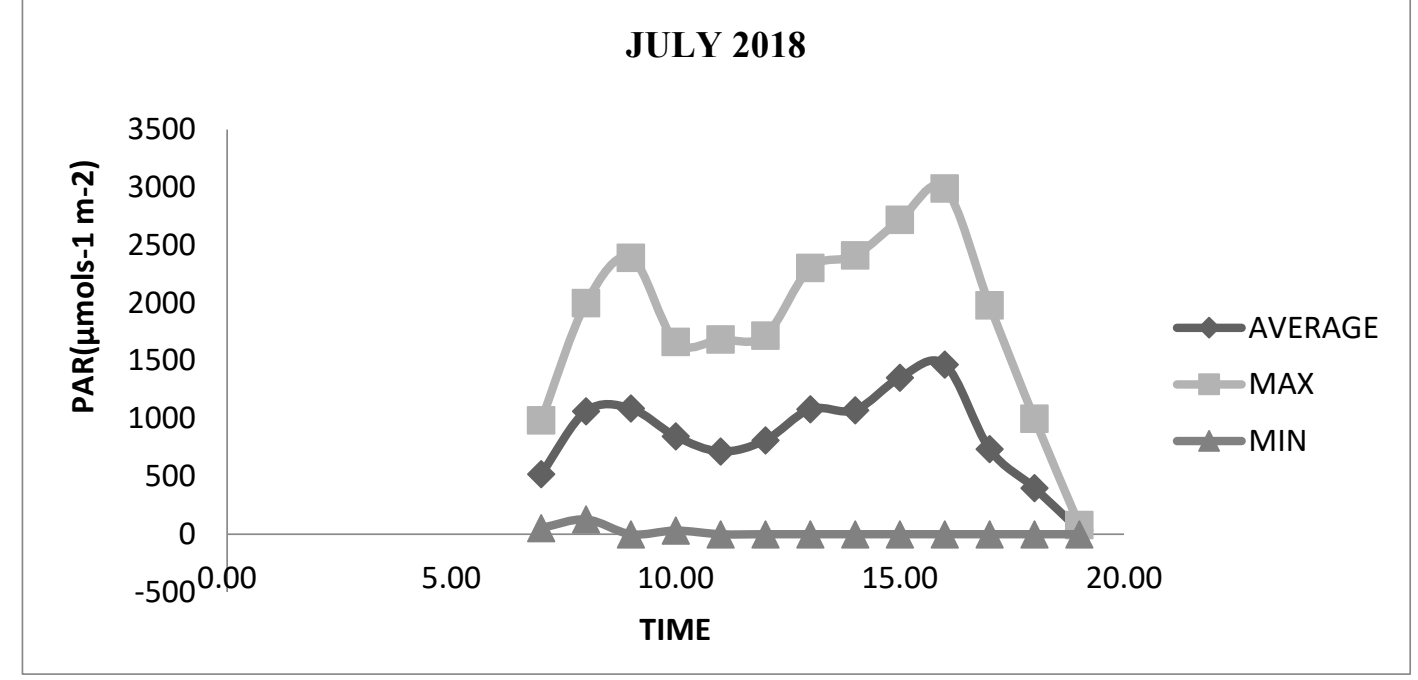

(b)

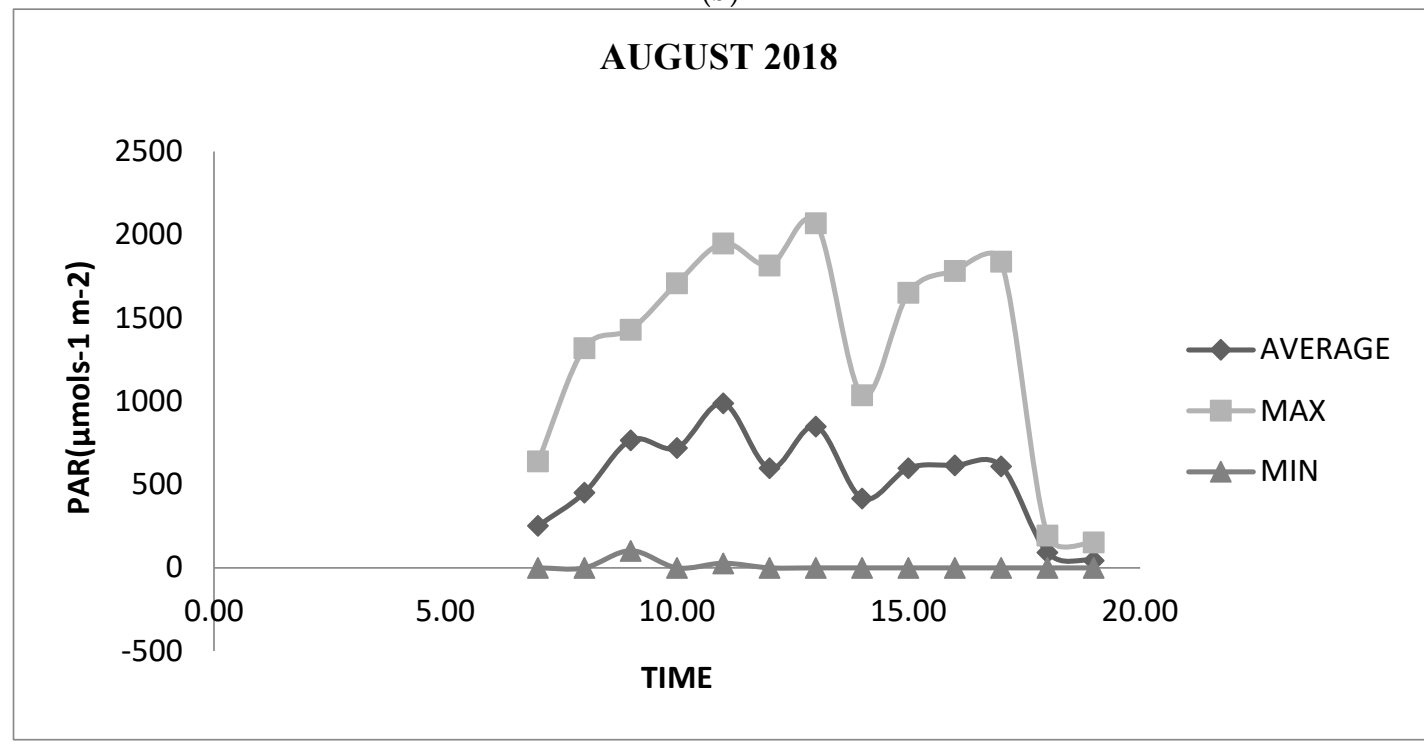

(c)

Figure A2. Cont. 


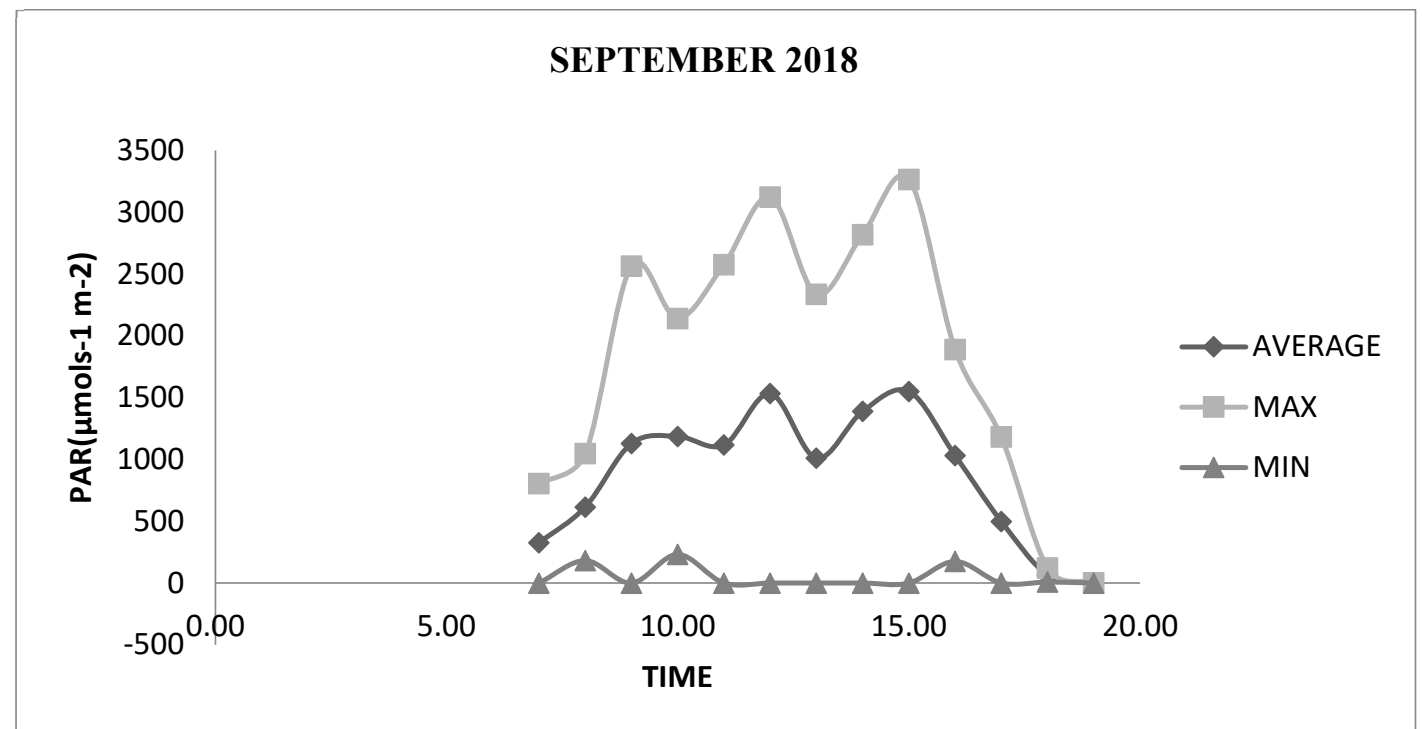

(d)

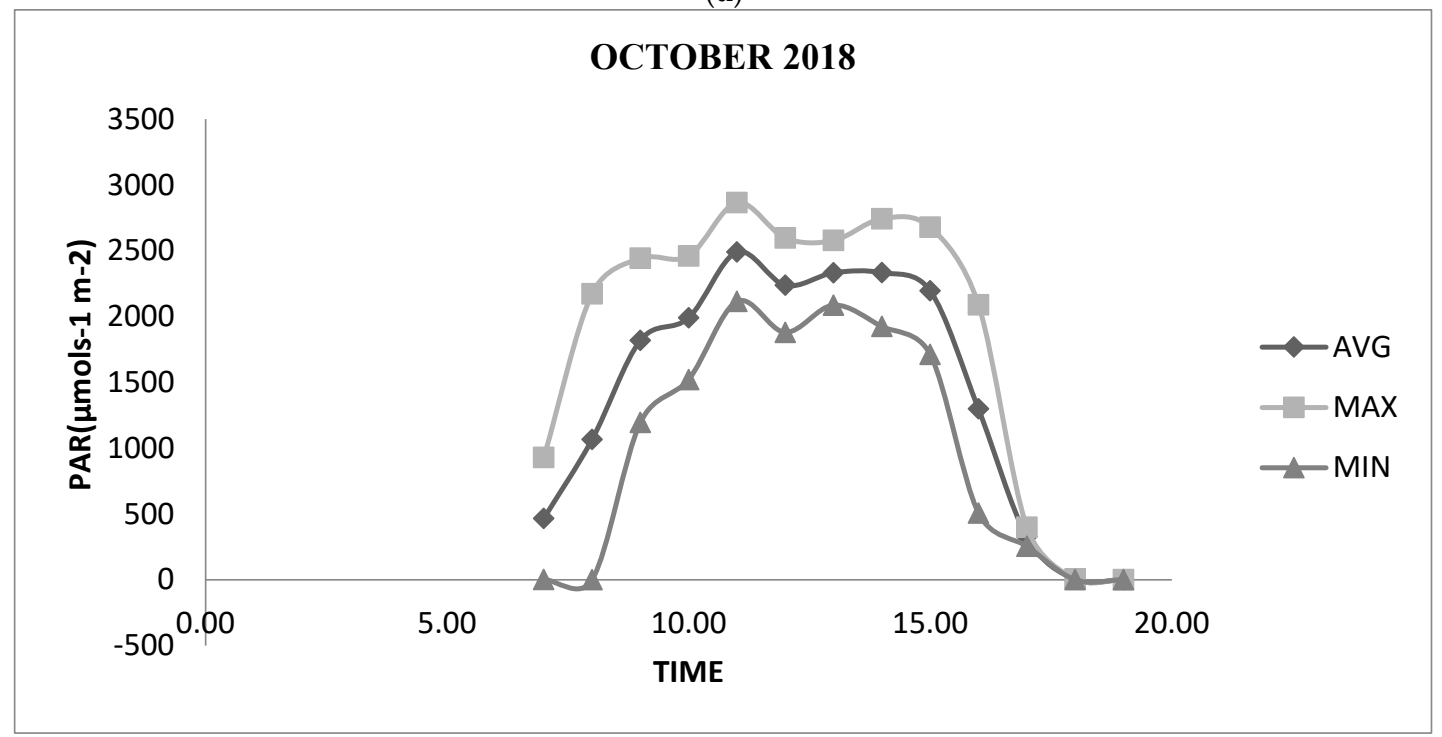

(e)

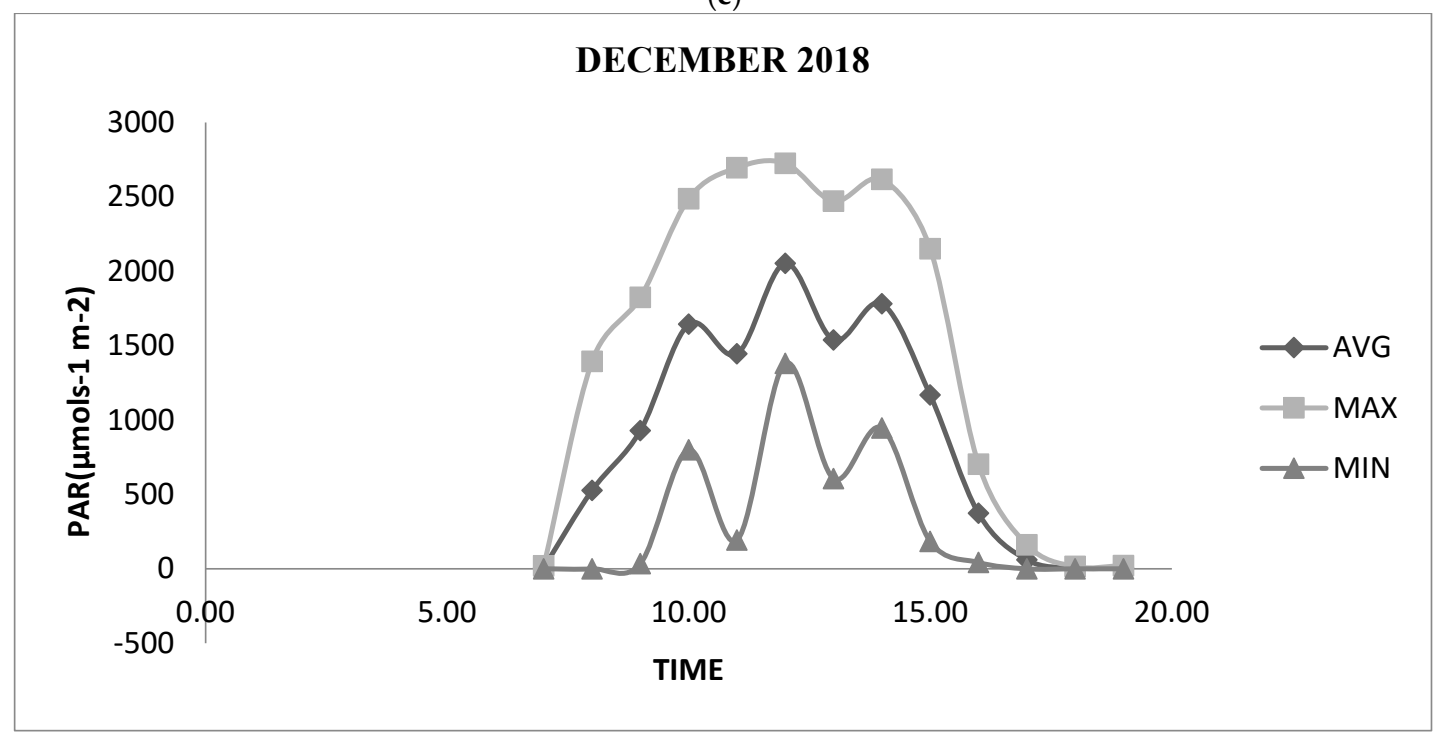

(f)

Figure A2. Cont. 


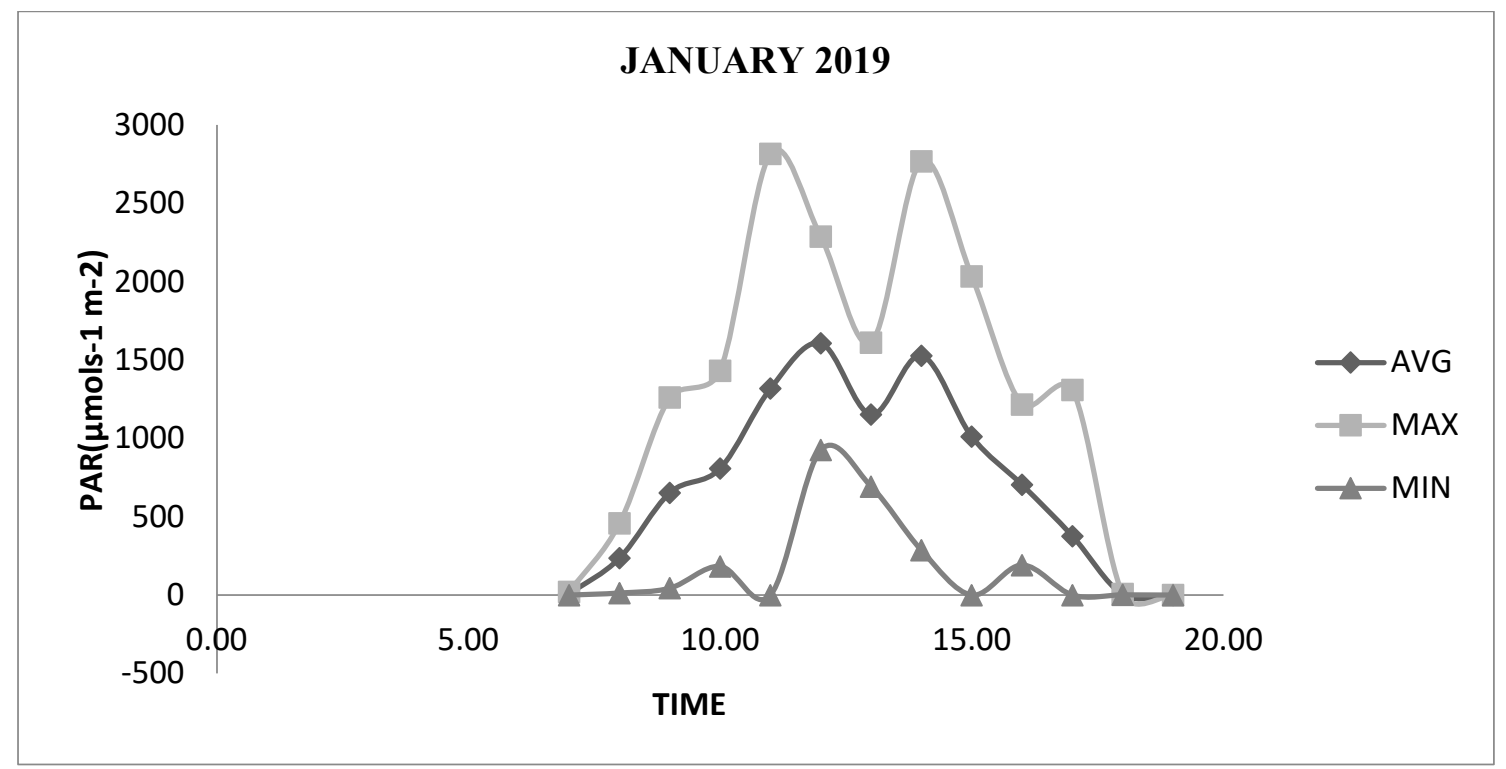

(g)

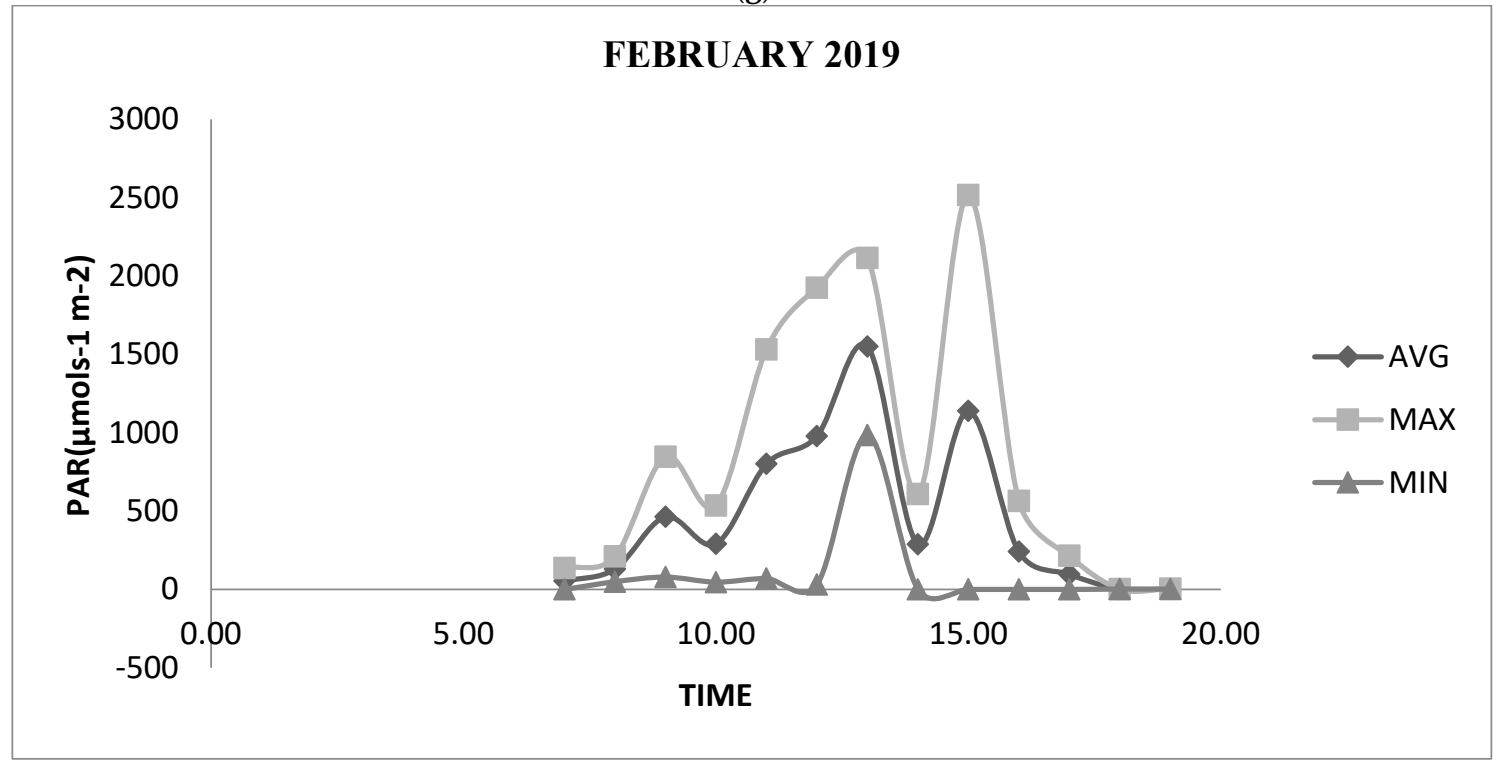

(h)

Figure A2. (a-h) Measured hour wise monthly average, maximum and minimum PAR for Roorkee. 
(a) September 2018

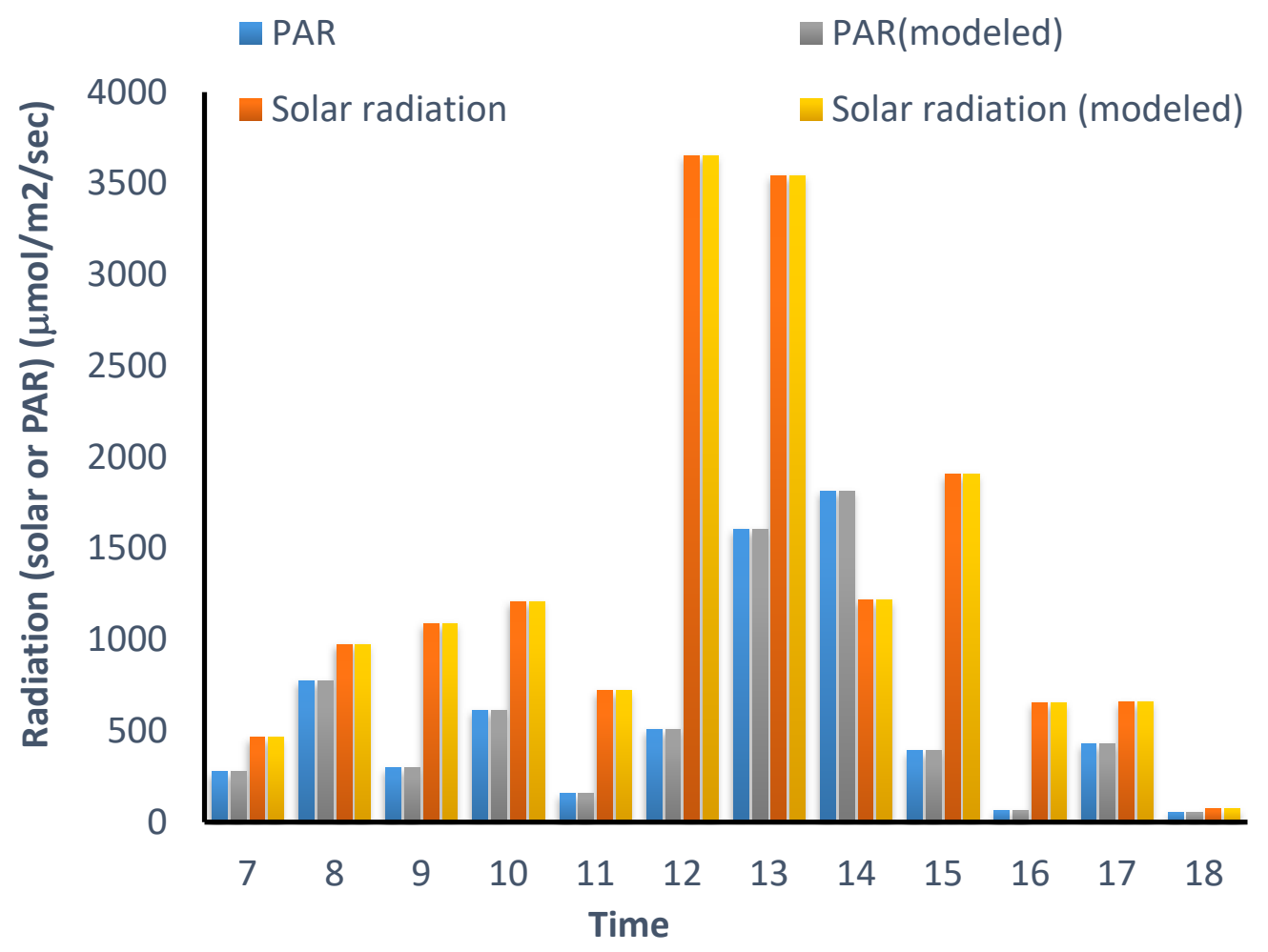

(b) December 2018

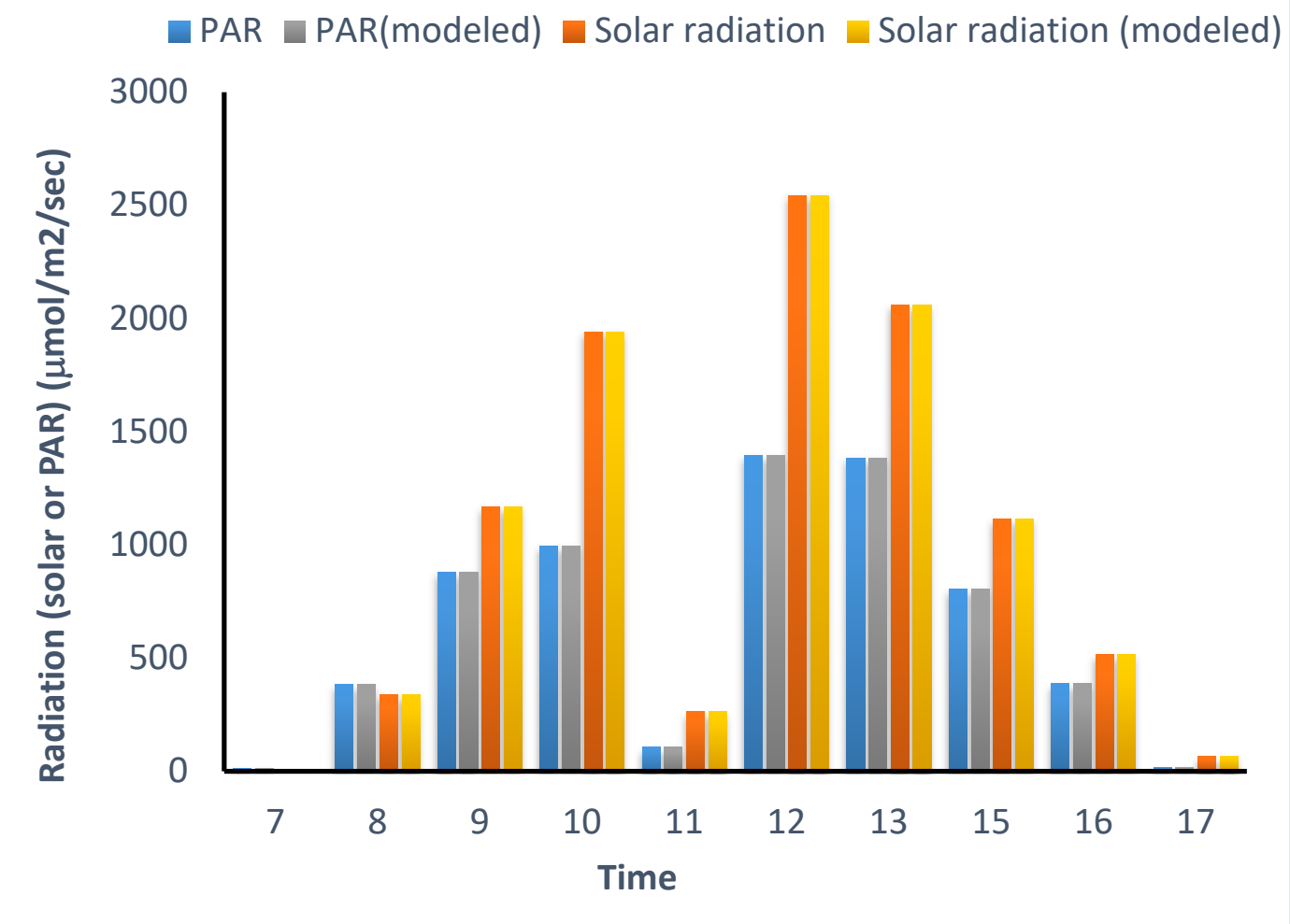

Figure A3. Cont. 
(c) January 2019

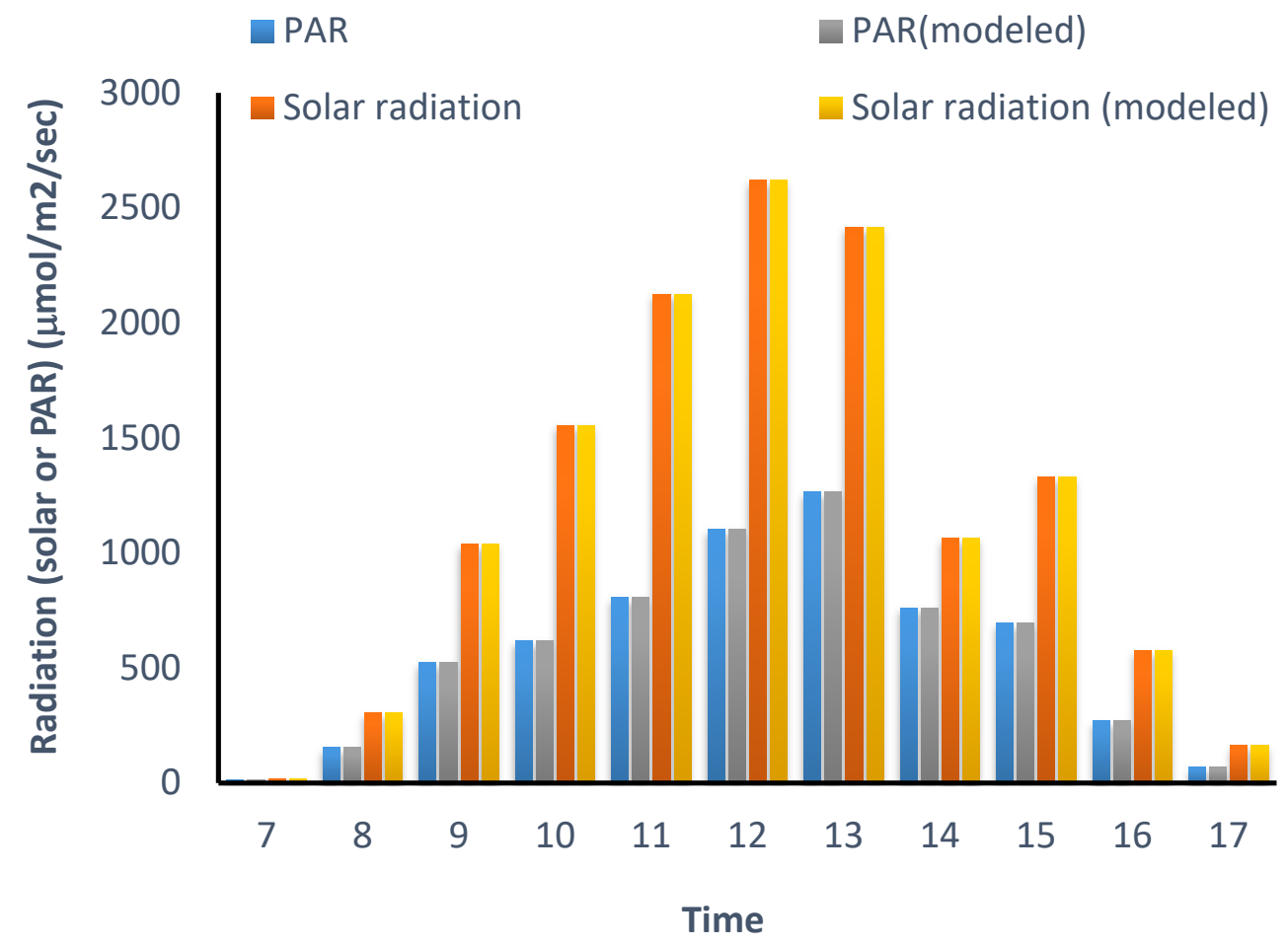

(d) February, 2019

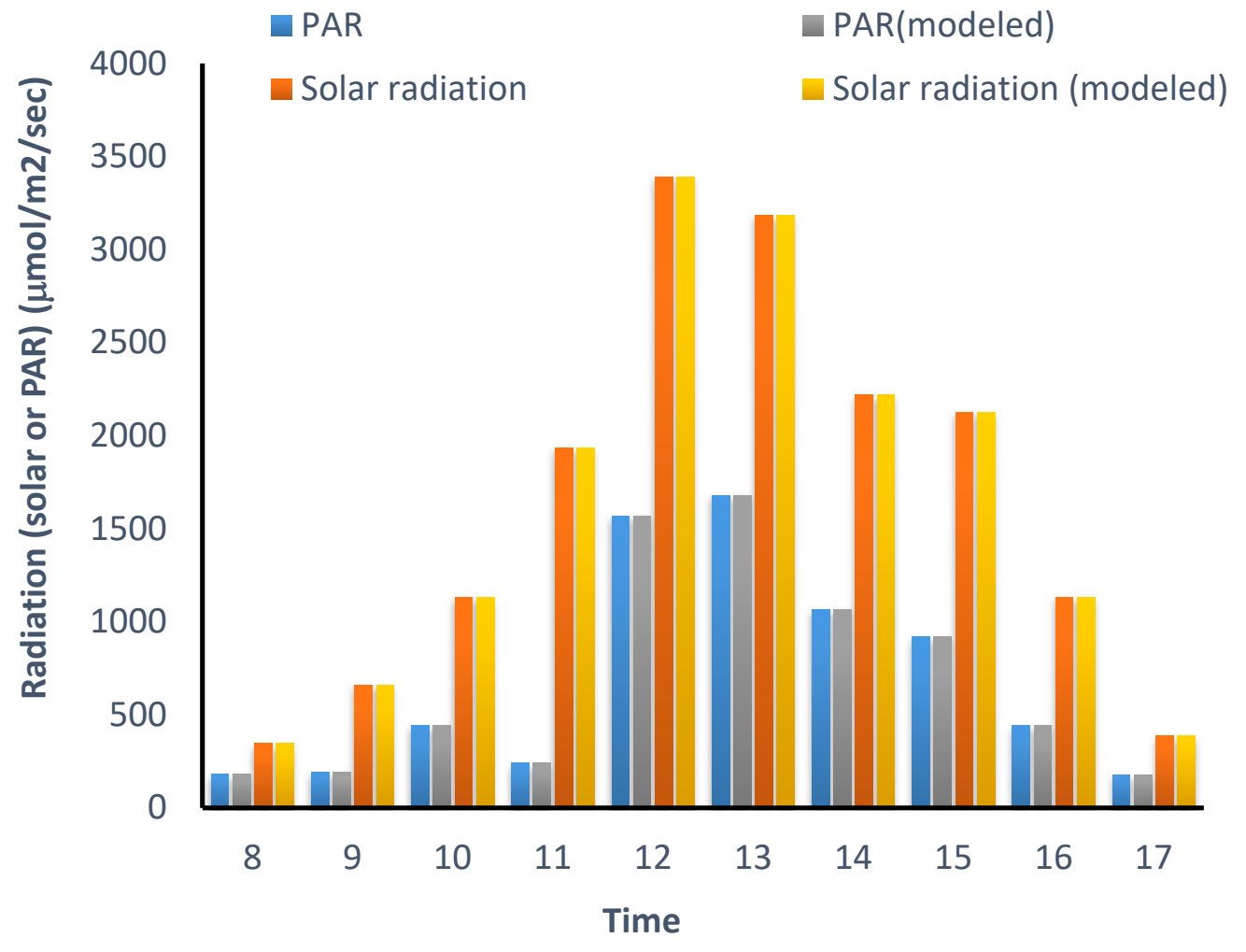

Figure A3. (a-d) Comparison between observed and modeled data for PAR. 


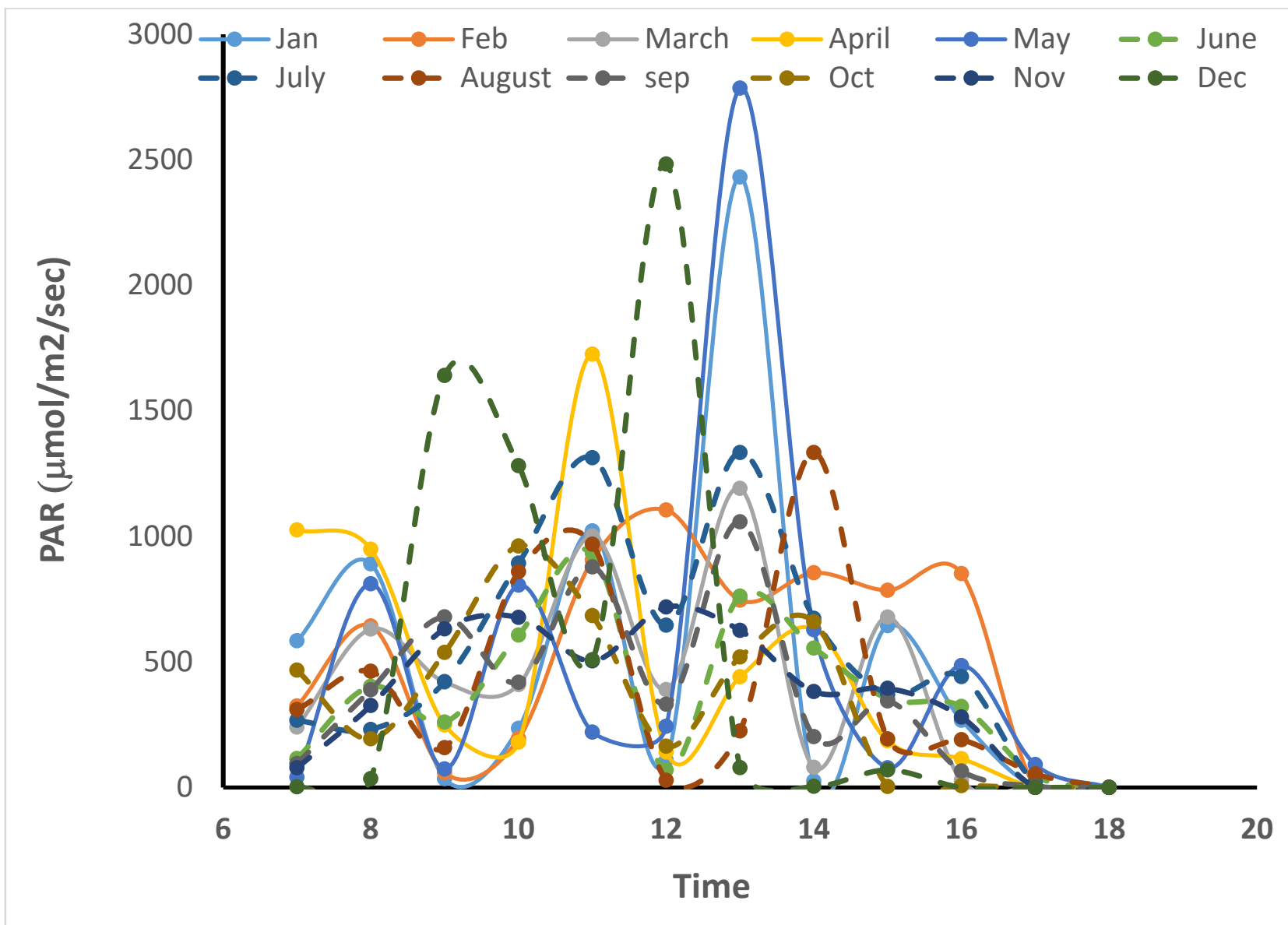

(a)

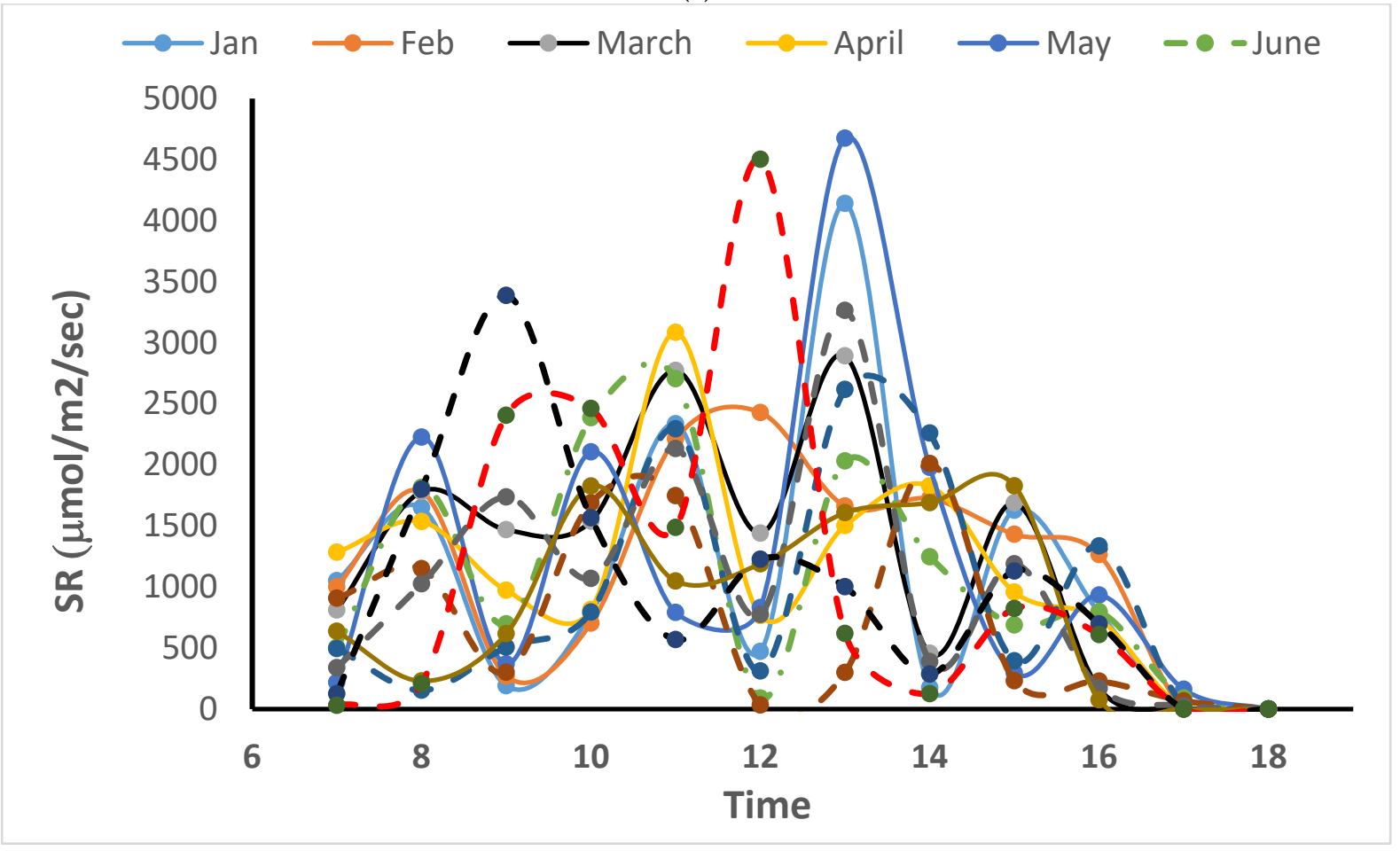

(b)

Figure A4. Simulated Solar radiation (a) and PAR (b) for Sorkoto, Nigeria. 


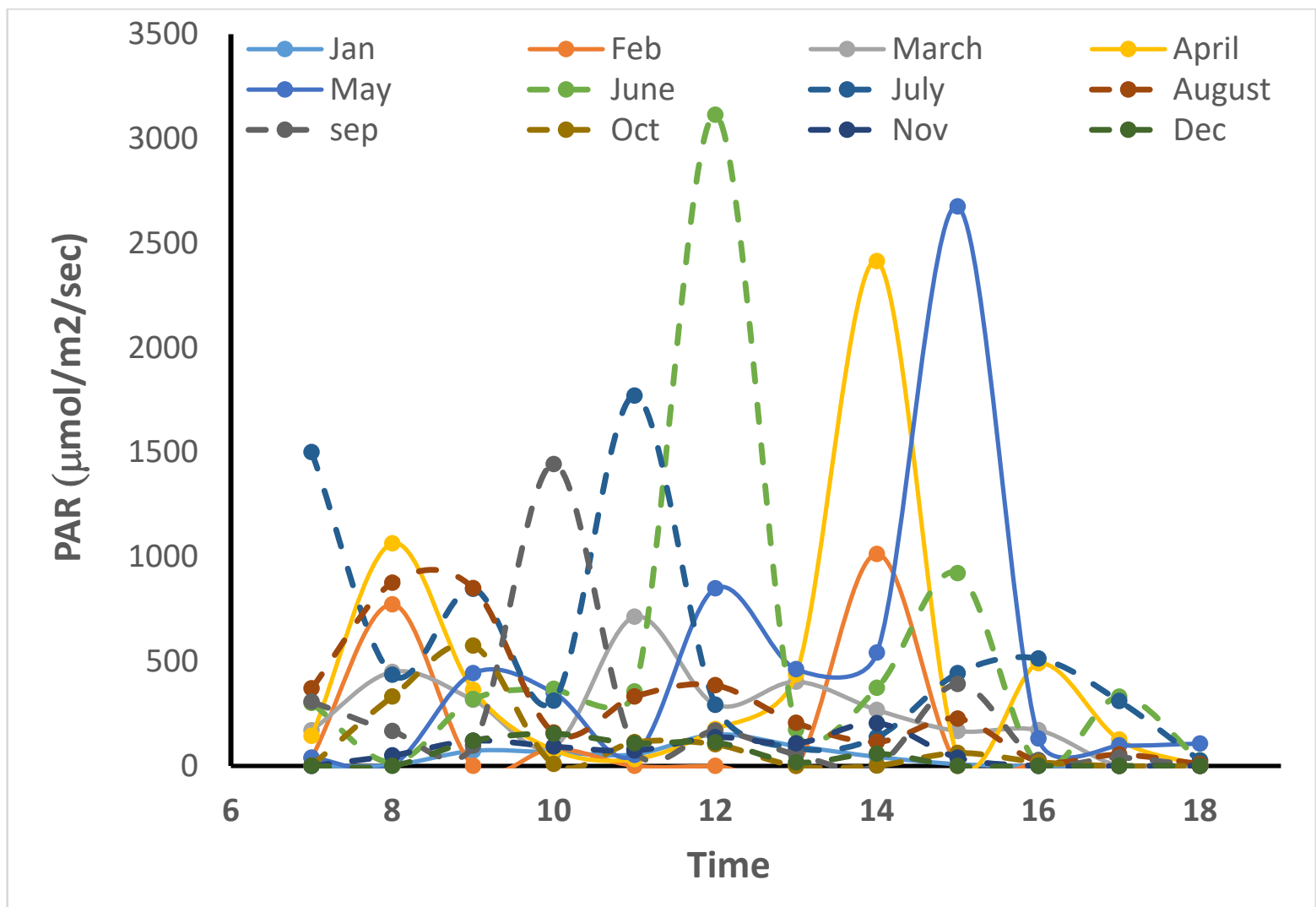

(a)

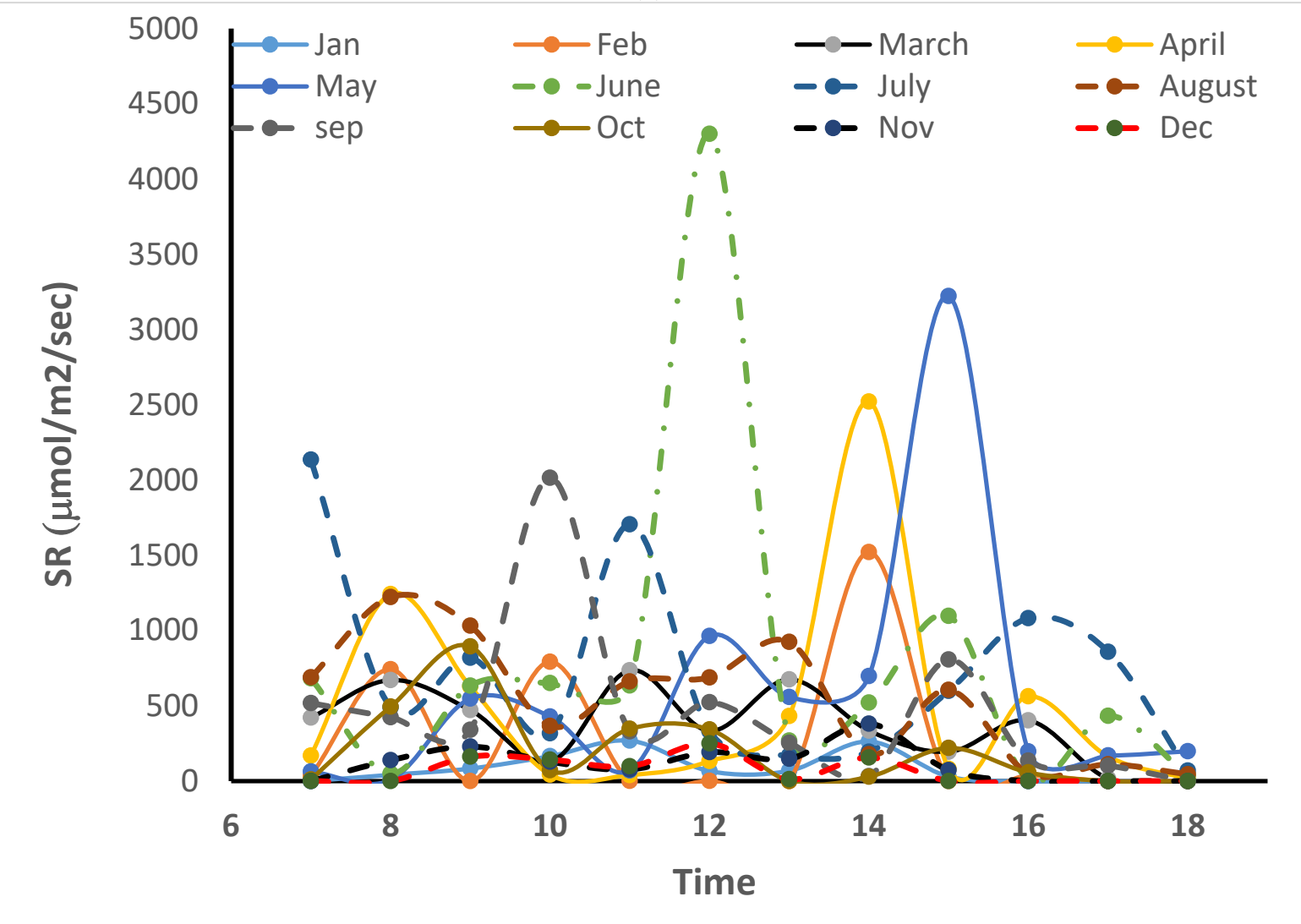

(b)

Figure A5. Simulated Solar radiation (a) and PAR (b) for Aberystwyth, UK. 


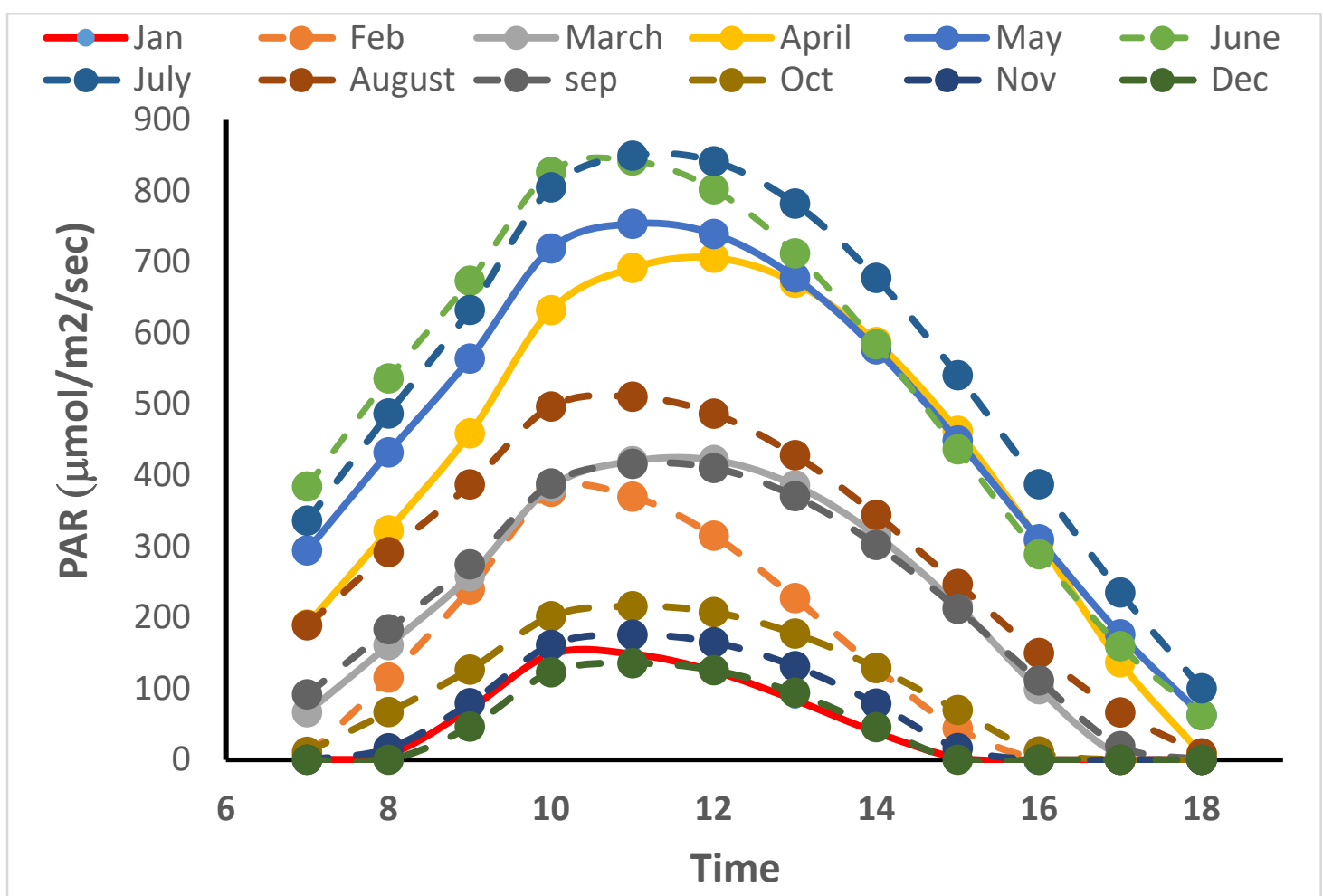

(a)

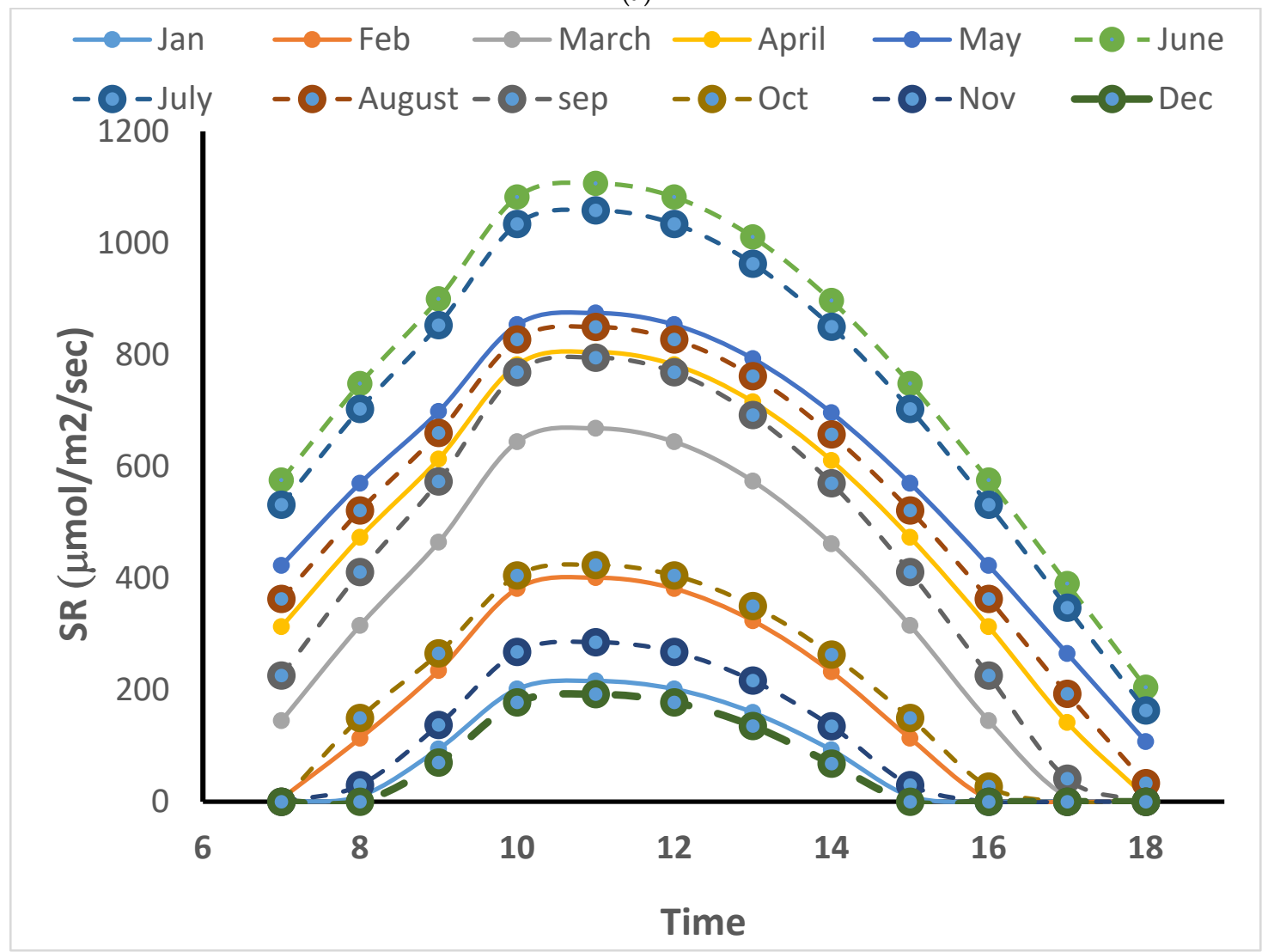

(b)

Figure A6. Simulated Solar radiation (a) and PAR (b) for Aberystwyth, UK using the modified model for smooth profile. 


\section{References}

1. Schmer, M.R.; Vogel, K.P.; Varvel, G.E.; Follett, R.F.; Mitchell, R.B.; Jin, V.L. Energy Potential and Greenhouse Gas Emissions from Bioenergy Cropping Systems on Marginally Productive Cropland. PLoS ONE 2014, 9, e89501. [CrossRef]

2. Hsu, D.D.; Inman, D.; Heath, G.A.; Wolfrum, E.J.; Mann, M.K.; Aden, A. Life cycle environmental impacts of selected US ethanol production and use pathways in 2022. Environ. Sci. Technol. 2010, 44, 5289-5297. [CrossRef]

3. Pate, R.; Klise, G.; Wu, B. Resource demand implications for US algae biofuels production scale-up. Appl. Energy 2011, 88, 3377-3388. [CrossRef]

4. Chisti, Y. Biodiesel from microalgae. Biotechnol. Adv. 2007, 25, 294-306. [CrossRef] [PubMed]

5. Chowdhury, R.; Freire, F. Bioenergy production from algae using dairy manure as a nutrient source: Life cycle energy and greenhouse gas emission analysis. Appl. Energy 2015, 154, 1112-1121. [CrossRef]

6. Sutherland, D.L.; Turnbull, M.H.; Craggs, R.J. Increased pond depth improves algal productivity and nutrient removal in wastewater treatment high rate algal ponds. Water Res. 2015, 53, 271-281. [CrossRef]

7. Iluz, D.; Abu-Ghosh, S. A novel photobioreactor creating fluctuating light from solar energy for a higher light-to-biomass conversion efficiency. Energy Convers. Manag. 2016, 126, 767-773. [CrossRef]

8. Xue, S.; Zhang, Q.; Wu, X.; Yan, C.; Cong, W. A novel photobioreactor structure using optical fibers as inner light source to fulfill flashing light effects of microalgae. Bioresour. Technol. 2013, 138, 141-147. [CrossRef] [PubMed]

9. Wondraczek, L.; Batentschuk, M.; Schmidt, M.; Borchardt, R.; Scheiner, S.; Seemann, B.; Schweizer, P.; Brabec, C.J. Solar spectral conversion for improving the photosynthetic activity in algae reactors. Nat. Commun. 2013, 4, 2047. [CrossRef]

10. Poblete, R.; Painemal, O. Improvement of the solar drying process of sludge using thermal storage. J. Environ. Manag. 2020, 255, 109883. [CrossRef]

11. Chong, K.K.; Onubogu, N.O.; Yew, T.K.; Wong, C.W.; Tan, W.C. Design and construction of active daylighting system using two-stage non-imaging solar concentrator. Appl. Energy 2017, 207, 45-60. [CrossRef]

12. Pearce, M.; Shemfe, M.; Sansom, C. Techno-economic analysis of solar integrated hydrothermal liquefaction of microalgae. Appl. Energy 2016, 166, 19-26. [CrossRef]

13. Yu, X.; Wu, Z.; Jiang, W.; Guo, X. Predicting daily photosynthetically active radiation from global solar radiation in the Contiguous United States. Energy Convers. Manag. 2015, 89, 71-82. [CrossRef]

14. Qin, J.; Yang, K.; Liang, S.; Tang, W. Estimation of daily mean photosynthetically active radiation under all-sky conditions based on relative sunshine data. J. Appl. Meteorol. Climatol. 2012, 51, 150-160. [CrossRef]

15. Chukwujindu, N.S.; Ogbulezie Julie, C.; Kabele, T.C.; Alwell, S.J.J. Estimations of photosynthetically active radiation over different climatic zones in Nigeria. SPC J. Energy. 2018, 1, 1-8.

16. Hocaoğlu, F.O. Novel analytical hourly solar radiation models for photovoltaic based system sizing algorithms. Energy Convers. Manag. 2010, 51, 2921-2929. [CrossRef]

17. Hocaoğlu, F.O. Stochastic approach for daily solar radiation modeling. Solar Energy 2011, 85, 278-287. [CrossRef]

18. Bhardwaj, S.; Sharma, V.; Srivastava, S.; Sastry, O.S.; Bandyopadhyay, B.; Chandel, S.S.; Gupta, P.J.R. Estimation of solar radiation using a combination of Hidden Markov Model and generalized Fuzzy model. Solar Energy 2013, 93, 43-54. [CrossRef]

19. Vindel, J.M.; Polo, J. Markov processes and Zipf's law in daily solar irradiation at earth's surface. J. Atmos. Sol.-Terr. Phys. 2014, 107, 42-47. [CrossRef]

20. Sudhakar, K.; Srivastava, T.; Satpathy, G.; Premalatha, M. Modelling and estimation of photosynthetically active incident radiation based on global irradiance in Indian latitudes. Int. J. Energy Environ. Eng. 2013, 4, 21. [CrossRef]

21. Sun, Z.; Liu, J.; Zeng, X.; Liang, H. Parameterization of instantaneous global horizontal irradiance: Cloudy-Sky component. J. Geophys. Res. Atmos. 2012, 117, D14. [CrossRef]

22. Amrouche, B.; Le Pivert, X. Artificial neural network based daily local forecasting for global solar radiation. Appl. Energy 2014, 130, 333-341. [CrossRef]

23. Davò, F.; Alessandrini, S.; Sperati, S.; Delle Monache, L.; Airoldi, D.; Vespucci, M.T. Post-processing techniques and principal component analysis for regional wind power and solar irradiance forecasting. Solar Energy 2016, 134, 327-338. [CrossRef]

24. Shams, M.B.; Haji, S.; Salman, A.; Abdali, H.; Alsaffar, A. Time series analysis of Bahrain's first hybrid renewable energy system. Energy 2016, 103, 1-15. [CrossRef]

25. Ajayi, O.O.; Ohijeagbon, O.D.; Nwadialo, C.E.; Olasope, O. New model to estimate daily global solar radiation over Nigeria. Sustain. Energy Technol. Assess. 2014, 5, 28-36. [CrossRef]

26. Yadala, S.; Cremaschi, S. Design and optimization of artificial cultivation units for algae production. Energy 2014, 78, 23-39. [CrossRef]

27. Dhimish, M.; Holmes, V.; Mather, P.; Sibley, M. Preliminary assessment of the solar resource in the United Kingdom. Clean Energy 2018, 2, 112-125. [CrossRef]

28. Adejumo, A.O.; Suleiman, E.A.; Okagbue, H.I. Exploration of solar radiation data from three geo-political zones in Nigeria. Data Brief 2017, 13, 60-68. [CrossRef]

29. Hu, B.; Wang, Y. Comparison of multi-empirical estimation models of photosynthetically active radiation under all sky conditions in Northeast China. Theor. Appl. Climatol. 2014, 116, 119-129. [CrossRef]

30. Available online: https://www.nestoria.in/roorkee/property/sale (accessed on 18 February 2019). 
31. Available online: https:/ / homes.mitula.com.ng / detalle $/ 238612 / 1610119585150072117 / 3 / 8 /$ landssokoto?page $=2 \& p o s=3 \& t$ sec=190\&t_or=2\&t_pvid=7b3a4c4a-bf3d-434f-b7c9-7c626d3ec178 (accessed on 21 May 2020).

32. Available online: https:/ / www.onthemarket.com/details/8422968/ (accessed on 30 May 2020).

33. Friedler, E.; Pisanty, E. Effects of design flow and treatment level on construction and operation costs of municipal wastewater treatment plants and their implications on policy making. Water Res. 2006, 40, 3751-3758. [CrossRef]

34. Voyant, C.; Muselli, M.; Paoli, C.; Nivet, M.L. Optimization of an artificial neural network dedicated to the multivariate forecasting of daily global radiation. Energy 2011, 36, 348-359. [CrossRef]

35. Liu, J.; Liu, J.; Linderholm, H.W.; Chen, D.; Yu, Q.; Wu, D.; Haginoya, S. Observation and calculation of the solar radiation on the Tibetan Plateau. Energy Convers. Manag. 2012, 57, 23-32. [CrossRef]

36. Available online: http://www.synergyenviron.com/tools/solarirradiance/Jaipur\%252CRajasthan\%252CIndia (accessed on 12 February 2019).

37. Hognon, C.; Delrue, F.; Boissonnet, G. Energetic and economic evaluation of Chlamydomonas reinhardtii hydrothermal liquefaction and pyrolysis through thermochemical models. Energy 2015, 93, 31-40. [CrossRef]

38. Davis, R.; Markham, J.; Kinchin, C.; Grundl, N.; Tan, E.C.; Humbird, D. Process Design and Economics for the Production of Algal Biomass: Algal Biomass Production in Open Pond Systems and Processing through Dewatering for Downstream Conversion (No. NREL/TP-5100-64772); National Renewable Energy Lab. (NREL): Golden, CO, USA, 2016.

39. Chowdhury, R.; Keen, P.L.; Tao, W. Fatty acid profile and energy efficiency of biodiesel production from an alkaliphilic algae grown in the photobioreactor. Bioresour. Technol. Rep. 2019, 6, 229-236. [CrossRef]

40. Chowdhury, R.; Franchetti, M. Life cycle energy demand from algal biofuel generated from nutrients present in the dairy waste. Sustain. Prod. Consum. 2017, 9, 22-27. [CrossRef]

41. Sanwal, V.; Chowdhury, R.; Sadhukhan, J. Optimization life cycle net energy of algal biofuel production. In Sustainable Utilization of Natural Resources; CRC Press: Boca Raton, FL, USA, 2017; pp. 581-593.

42. Chowdhury, R.; Sadhukhan, J.; Traverso, M.; Keen, P.L. Effects of residence time on life cycle assessment of bioenergy production from dairy manure. Bioresour. Technol. Rep. 2018, 4, 57-65. [CrossRef]

43. Acién, F.G.; Fernández, J.M.; Magán, J.J.; Molina, E. Production cost of a real microalgae production plant and strategies to reduce it. Biotechnol. Adv. 2012, 30, 1344-1353. [CrossRef] [PubMed]

44. Delrue, F.; Setier, P.A.; Sahut, C.; Cournac, L.; Roubaud, A.; Peltier, G.; Froment, A.K. An economic, sustainability, and energetic model of biodiesel production from microalgae. Bioresour. Technol. 2012, 111, 191-200. [CrossRef] [PubMed]

45. Rani, S.; Chowdhury, R.; Tao, W.; Nedbalova, L. Microalga-Mediated tertiary treatment of municipal wastewater: Removal of nutrients and pathogens. Sustainability 2021, 13, 9554. [CrossRef]

46. Ambat, I.; Tang, W.Z.; Sillanpää, M. Statistical analysis of sustainable production of algal biomass from wastewater treatment process. Biomass Bioenergy 2019, 120, 471-478. [CrossRef]

47. Pegallapati, A.K.; Nirmalakhandan, N. Internally illuminated photobioreactor for algal cultivation under carbon dioxidesupplementation: Performance evaluation. Renew. Energy 2013, 56, 129-135. [CrossRef]

48. John, S.G.; Lakshmanan, T. Cost optimization of dish solar concentrators for improved scalability decisions. Renew. Energy 2017, 114, 600-613. [CrossRef]

49. Sander, K.; Murthy, G.S. Life cycle analysis of algae biodiesel. Int. J. Life Cycle Assess. 2010, 15, 704-714. [CrossRef]

50. Safaei, A.; Freire, F.; Antunes, C.H. A model for optimal energy planning of a commercial building integrating solar and cogeneration systems. Energy 2013, 61, 211-223. [CrossRef]

51. Rigter, J.; Vidican, G. Cost and optimal feed-in tariff for small scale photovoltaic systems in China. Energy Policy 2010, 38, 6989-7000. [CrossRef]

52. Maes, D.; Van Passel, S. Interference of regional support policies on the economic and environmental performance of a hybrid cogeneration-solar panel energy system. Energy Policy 2012, 42, 670-680. [CrossRef]

53. Lopez-Ruiz, H.G.; Blazquez, J.; Vittorio, M. Assessing residential solar rooftop potential in Saudi Arabia using nighttime satellite images: A study for the city of Riyadh. Energy Policy 2020, 140, 111399. [CrossRef]

54. Chowdhury, R.; Viamajala, S.; Gerlach, R. Reduction of environmental and energy footprint of microalgal biodiesel production through material and energy integration. Bioresour. Technol. 2012, 108, 102-111. [CrossRef]

55. Ischia, G.; Orlandi, M.; Fendrich, M.A.; Bettonte, M.; Merzari, F.; Miotello, A.; Fiori, L. Realization of a solar hydrothermal carbonization reactor: A zero-energy technology for waste biomass valorization. J. Environ. Manag. 2020, 259, 110067. [CrossRef]

56. Kumar, D.; Kumar, S. Thermal performance of the solar parabolic trough collector at different flow rates: An experimental study. Int. J. Ambient. Energy 2018, 39, 93-102. [CrossRef] 